MIECZYSŁAW WRZOSEK (Warszawa)

\title{
DOKUMENTY DOTYCZĄCE SPRAWY POLSKIEJ PODCZAS PIERWSZEJ WOJNY ŚWIATOWEJ (MAJ - SIERPIEŃ 1917) CZEŚĆ III
}

Części pierwsza i druga tych dokumentów zaczerpniętych $\mathrm{z}$ zasobów Haus, - Hof und Staatsarchiv w Wiedniu były ogłoszone w dwóch kolejnych rocznikach ,Studiów Podlaskich", to znaczy: część I w X tomie z 2000 roku, a część II w XI tomie z 2001 roku. Ta część dokumentów, które są publikowane w tomie niniejszym ma częściowo zmieniony tytuł. Zostało to spowodowane ówczesnymi losami brygadiera Józefa Piłsudskiego, który 22 lipca 1917 r. zostal aresztowany w Warszawie przez niemieckie władze okupacyjne Królestwa Polskiego i przebywał w twierdzy Magdeburg jako więzień polityczny. W obecnie publikowanych dokumentach w związku z tym jest wymieniany tylko sporadycznie. Aktualna była natomiast kwestia polska i sprawa Legionów Polskich. Tych właśnie kwestii dotyczą dokumenty części III i mają bardzo duże znaczenie, ponieważ odzwierciedlają spór niemiecko-austriacki o sposób rozwiązania kwestii polskiej, jak też sprawy Legionów Polskich po tak zwanym kryzysie przysięgowym z przełomu pierwszej i drugiej dekady lipca 1917 r.

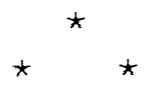

\section{Dokument nr 1}

1917 maj 8, Wiedeń. - Pismo ministra austriackiej Obrony Krajowej dotyczqce przeprowadzenia doktadnego, komisyjnego przebadania rannych $i$ chorych legionistów $w$ zakładach leczniczych na niemieckim $i$ austro-węgier- 
skim obszarze okupacyjnym $w$ celu wykrycia zdolnych do wznowienia czynnej stuzby wojskowej.

Eine aus Delegierten der östereichisch-ungarischen und der deutschen Heeresleitung zusammengesetzte ärztliche Kommission bereist die Heilanstalten in Lublin, Dęblin, Radom, Kielce, Krakau, Rabka, Zakopane, Kamieńsk, Petrikau, Warschau, Zegrze, Modlin, Ostrów, Ostrołęka und Zmbrow, um ïber die dortselbst befindlichen verwundeten (kranken) Angehörigen des polnisches Hilfskorps nach vorheriger Überprïfung ihres Tauglichkeitgrades zu entscheiden, ob sie in die polnische Wehrmacht zu ïbernehmen oder aus dem polnischechen Hilfskorps zu entlassen sind.

Diese Kommission ist bereits durch das kaiserliche deutsche General Gouvernement in Warschau angewiesen, solche Angehörige des polnischen Hilfskorps österreichische oder ungarische Staatsanhehörigkeit (Offizieren und Mannschaften), die von der Kommission in die polnische Wehrmacht nicht ïbernommen worden, nach ihrer Spitalsentlassung ausnahmslos zum k.k. Landwehr Ergänzungs Bezirk Kommando in Krakau abzusenden.

Das genannte Landwehr Ergänzungs Bezirk Kommando hat zunächst das Wehrpflichtverhältnis dieser Angehörige des polnischen Hilfskorps festzustellen und dann alle, ausgenommen solche, die weder dienst - noch landsturmpflichtig sind oder die in der Zeit bis 30 November $1916 \mathrm{zu}$ jedem Landsturmdienste ungeeignet Klassifizierten, der Superarbitrierung zu unterziehen; dieses Verfahren hat beim Landwehr Ergänzungs Bezirk Kommando Krakau nach den für Personen der bewaffneten Macht diesbezïglich festgelegten Grundsätzen stattzufinden.

Nicht Dienst - oder Leistung Pflichtige und bis 30 November $1916 \mathrm{zu}$ jedem Leistung Dienste ungeeignet Klassifizierte sind zu entlasen, letztere aber unmittelbar nach ihrer Entlassung auf Grund der Einberufungskundmachung "T" vom 18 April 1917 bezwïglich der analogen ungarischen Einberufungskundmachung weiter zu bahandeln.

Alle übrige angehörigen des polnischen Hilfskorps (Offiziere un Mannschaften) sind nach durchgeführten Super Verfahren wie folgt zu behandeln;

1) zu jedem Leistung Dienste klassifizierte Mannschaftspersonen sind zu entlassen; hievon ist daszuständige k.u.k. (k.k.) Ergänzungs Bezirk Kommando (Leistung Bezirk Kommando) und die polnische Bezirksbehörde zu verständigen;

2) alle ïbrigen nicht zu jedem Dienste ungeeignet Klassifizierten sind je nach ihrer Zugehörigkeit und zwar die Heeres (Landwehr) Dienstpflichtigen zum zuständigen Heeres - (Landwehr) Ersatzkörper, die Land- 
sturm Pflichtigen zum Zuständigen Landsturm Bezirk Kommando zur weiteren Erfüllung ihrer Dienstleistung Pflicht abzusenden;

3) Legions Offiziere (Fähnriche) sind vorläufig zu keiner weiteren militäre Dienstleistung heranzuziehen, sondern vom Landwehr Ergänzungs Bezirk kommando Krakau ohne Riicksicht ob sie im wehrpflichtigen Alter stehen oder nicht, bis zur hiesigen ähnlichen Entscheidung zu beurlauben.

Sämtliche Legionsoffiziere, die von der Bezeichneten ärtlzlichen Kommission zum Landwehr Ergenzungs Bezirk Kommando Krakau abgesendet wurden, sind unverziiglich monativ zu melden und hiebei anzuführen:

a) Geburtsjahr- Ort, Bezirk, Heimatberechtigung (Heimatzuständigkeit),

b) ob Anspruch auf Begiinstigung zum Einjährige, Freiwillige Dienst.

c) Lebensstellung,

d) Charge, Rang, Standverhältnis et cetera in der bewaffneten Macht der österreichisch-ungarische Monarchie, bisherige Evidenzbehörde,

e) Dienstzeit im polnischen Hilfskorps, darunter wie lange in der Kampfront.

f) seit wann in der dermaligen Legions Offizier Charge und

g) erworbene Verdienste vor dem Feinde Auszeichnungen et cetera

Bezüglich Anerkennung der in polnischen Hilfskorps erreichneten Unteroffiziers Charge beim Eintritt in das gemeinsame Heer (in die k.k. Landwehr) wird auf den Erlass Abteilung 2/St. Nr. 34226 vom 7 Jänner 1917 aufmerksam gemacht.

Anzahl der zum Landwehr Ergäzungs Bezirk Kommando Krakau jeweilig einrückenden Mannschaftspersonen des polnisches Hilfskorps, darunter wieviel zur Erfüllung ihrer Dienst (Leistung) Pflicht verhalten wurden, ist fallweise $z u$ melden.

Ergeht an Militär Kommando Krakau das Landwehr Ergänzungs Bezirkkommando Krakau und abschriftlich zur Kentnisannahme an das Kommando des polnisches Hilfskorps Warschau, das Armee Oberkommando (Q. Abteilung), das General Gouvernement Lublin, den Vertreter des Armee Oberkominndo beim kaiserlich deutschen General Gouvernement Warschau, das Kriegs Ministerium, den königliche ungarische Landwehr Budapest, den Chef des Ersatzwesens Wien und an alle iibrigen Militär Kommandos.

In Vertretung des Ministers Czapp m.p. FML

Kopia, maszynopis.

Haus, - Hof und Staatsarchiv, Krieg, PA I, karton 1025, plik $\beta$ [eta], folio 82-84. 


\section{Dokument nr 2}

1917 czerwiec 17, Wieden. - Telegram nr 397 austro-węgierskiego Ministerstwa Spraw Zagranicznych do radcy austro-węierskiej ambasady w Berlinie hrabiego F. Larischa von Moennich i do szefa austro-wegierskiego Sztabu Generalnego Artura Arza von Strassenberga o zapowiedzi generata Hansa uon Beselera w sprawie tylko częściowego wykorzystania Legionów Polskich jako kadry przysztego Wojska Polskiego.

Nach allen mir zukommenden Meldungen droht wegen der polnischen Armeefrage, und zwar speziell aus Anlass der Haltung, die General von Beseler in letzter Zeit in dieser Angelegenheit eingenommen hat, neuerlich der durch unsere Antwort an den polnischen Staatsrat bis zu einem gewissen Grade beschworene Ausbruch einer politischen Krise in Polen, welche die Demission des Staatsrates und den den Beykott der von den Zentralmächten ins Leben gerufen, beziehungsweise in Ansicht gestallten staatlichen Institutionen zur Folge könnte.

Obwohl bekanntlich nicht wir es waren, die bei der Übergabe der poInischen Legionen das Verlegen gestellt haben, dass die österreichischen Staatsangehörigen nach kurzer Zeit aus diesen ausgeschieden wïrden, vielmehr diesbezüglich unserseits bei Abfassung der sogenannten Aprilvereinbarung ïber die polsnische Armee ausschlisslich dem Wunsche der deutschen Obersten Heeresleitung nachgegeben wurde, haben wir dennoch in loyaler Einhaltung dieser Abmachungen alle polnischen Faktoren gegenïber nach wie vor betont, dass der Gedanke der Eliminierung der Oesterreicher nicht politischen Rücksichten entspringe, vielmehr ausschliesslich dadurch veranlasst sie, dass das gesamte Legionenpersonal zu zahlreich wäre, um als Ausbildungskadre für die dermalen noch numerisch geringfügige polnische Armee zu dienen. Indessen hat General von Beseler unmittelbar vor der Überreichung unserer Antwort an den Staatsarat dadurch eine vollkommen neue Situation geschaffen, dass er den Staattsmitgliedern erkläte, die österreichischen Soldaten im polnischen Heere müssten bis 1 Juli die polnische Staatsbürgerschaft erwerben, widrigenfalls sie definitiv aus dem polnischen Heere ausgeschieden würden. A bgesehen von der Inopportunität einer solchen Erklärung, durch die zum ersten Male der kalendermässige Termin für die Ausscheidung der Oesterreicher öffentlich bekanntgegeben wurde, gerade vor Erteiling der Antwort auf das Staatsratsmemorandum, 
die hiedurch den grössten Teil ihrer Wirkung einbüsste, hat der Generalgouverneur durch seine Stellungsnahme den von den beidigen Heeresleitungen bisher festgehaltenen Standpunkt, dass die Ausscheidung eines Teilen der Legionäre aus der noch in Bildung begriffenen und daher im Hinterlande stationierten polnischen Armee einen Akt militärischer Oekonomie darstelle und keinerlei politischen Motiv enentspringe, verlassen, die Frage $z u$ einer ausschlisslich politischen gestempelt und durch seine Erklärung implicite das Verbleiben der ganzen Legion àls Kadre der polnischen Armee unter einer Bedingung als wïnschenswert bezeichnet. Dass nämlich die österreichischen Staatsbïrger die polnische Staatsangehörigkeit annehmen wüden. Durch letztere Anregung hat er ihne vorherige Rücksprache mit uns dem Polentum gegenüber Fragen aufgeworfen, die in alleerster Linie uns tangieren, und zu ihrer Lösung weittragende Vorschläge gemacht, von denen er selbst kaum annehmen konnte, dass sie uns genehm sein wiirden.

Euer Hochgeboren wollen dem Herrn Staatssaekretär nach Wiederholung obiger Darlegungen als meine Ansicht mitteilen, dass es bei der jetzigen Sachlage an dem dermalen mit der Aufstellung der polnischen Armee batrauten Warschauer Generalgouverneur liege, den ersten Schritt zur Beilegung der von ihm so wesentlich kømplizierten polnischen Heeresangelegenheit zu machen. Die Frage des Umfanges der für dieses Heer erfordrlichen Ausbildungskadres ist. abgesehen von ihren unleugbaren starken politischen Beigeschmack doch in erster Linie militärischer Natur.

Dementsprechend wäre es erforderlich, das Heer von Beseler zunächst in entschiedener Weise zur Frage Stellung nehme, ob vom militärischen Standpunkte aus tatsächlich zur Heranbildung der polnischen Armee, wie jetzt polnischeseits behauptet wird, die ganze Legion als Kadre benötigt wird oder ob dies, wie bisher seitens der Heeresleitungen angenommen wurde, eine grosse Verschwendundung an Soldatenmaterial bedeuten würde. Im letzteren Falle wäre es dringend angezeigt, dass Herr von Beseler diese Tatsache gegen ̈̈er den Polen konstatiere, wodurch freilich seine frïheren Erklärungen iiber die Ablegung der Staatbürgerschaft durch unsere Regierung behufs Verbleib in der polnischen Legionen implicite als der Aktualität entbehrend charakterisiert würden. Wäre aber den gegenwärtigen militärischen Verhältnissen nach wirklich der Verbleib der ganzen Legion als Kadre für die polnische Armee norwendig, so müsste im engen Einvernehmen zwischen uns und Deutschland und unter Verzicht auf für uns unannehmbare Lösungsformeln ein Ausweg gefunden werden, durch den, ohne die staatsbürgerliche Stellung unserer'Soldaten zu tangieren, die sogenannte Zerreis- 
sung der ehemaligen polnischen Legion vermieden werden könnte. Als letztes Auskunftsmittel für den Fall, als tatsächlich das Herausziehen der Soldaten österreichischer Staatsangehörigkeit aus dem polnischen Heer den gänzlichen Zerfall des letzteren und die Demission des Staatsrates zur Folge haben müsste, wäre die Abkommandierung der ganzen ehemaligen Legion an die Front in Erwägung zu ziehen.

Vom Standpunkte des politischen Interesses der Zentralmächte und speziell Deutschlands ist es schliesslich von entscheindender Wichtigkeit, dass die auf deutsche Initiative hin seinerzeit feierlich angekündigte und in Angriff genommene Heeresbildung nich mit einem vollständigen Fiasko endige. Ein solches wïrde, umsomehr als jetzt auch französischerseits, wie es scheint, durchaus nicht ohne Aussicht auf Erfolg, die Bildung einer polnischen Armee in Angriff genommen wird, im gesamten Auslande als nicht weniger symptomatisch für die vollige Abkehr Polens von den Zentralmäten und für den politischen Anschluss des Landes an die Entente aufgefasst werden, als etwa ein Zusammenbruch der von uns ins Leben gerufenen staatlichen Institutionen, welcher ïbrigens auch voraussichtlich sich als eine weitere Folge des Scheiterns der militärischrn Pläne Deutschalands in Polen ergeben würde.

Euer Hochgeboren wollen die vorstehenden Gesichtspunkte der kaiserlichen Regierung gegenïber entwickeln und dieselbe um eine baldige Bekanntgabe ihres Standpunktes in der Angelegenheit ersuchen.

Schliesslich wollen Euer Hochgeboren betonen, dass ich mich der Erwartung hingebe, dass die kaiserliche Regierung wie seinerzeit in Bezug auf unsere gemeinsame Stellungsnahme gegenüber dem möglichen Rücktritte des polnischen Staatsrates auch jetzt mit mir iiber die Notwendigkeit eines gemeinsamen zielbewussten Vorgehens in der Armeefrage eines Sinnes sein werde. Die Verwirklichung unserer gemeinsamen militärisch-politischen $\mathrm{Zu}$ kunftspläne in Polen wïrde bedenklich in Frage gestellt werden, wenn es den Okkupanten ganz Polens nicht gelingen sollte, daselbst eine nationale Armee, wenn auch im bescheidenen Umfange zu schaffen, während nach glaubwürdigen Meldungen die Bildung eines polnischen Korps aus den im Auslande zerstreuten Polen besonders im Falle des Misslingens unserer Armeepläne voraussichtlich zur Tatsache werden wïrde.

Fiir Baron Arz.

Nachstehend beehre ich mich, Euer Exzellenz den Inhalt eines von mir an den k.u.k. Gescheftsträger in Berlin gerichteten Erlasses, welcher sich 
mit der durch die inopportune Äuserung des Generals von Beseler über die Bedingungen des Verbleibens unserer Staatsangehörigen in der polnischen Armee geschaffennen Situation befasst, mittzuteilen.

Falls Euer Exzellenz, wie ich annehme, gleichfalls auf dem von mir eingenommenen Standpunkte stehen, würde ich Hochdieselben bitten, Ihren Vertreter bei der deutschen Obersten Heeresleitung anzuweisen, sich dieser gegenüber in möglichster Anlehnung an den Text meiner einschlägigen Weisung an den k.u.k. Geschäftsträger in Berlin zu äussern. Für eine seinerzeitige Mitteilung darüber, welche Aufnahme die vorstehenden Darlegungen bei der deutschen Obersten Heeresleitung gefunden haben, wäre ich Euer Exzellenz besonders verbunden.

Streng vertraulich möchte ich mir darauf hinzuweisen erlauben, dass es mir angesichts der grossen Erregung, die sowohl im Königreiche Polen wie unter den hiesigen galizischen Politikern wegen der sogenannten „Zerreissung der Legionen" herrscht, opportun erscheint, einerseits ostensibel unser Interesse an der polnischen Heeresbildung zu dokumentieren, anderseits die massgebenden deutschen militärischen Faktoren, die das Odium der von ihnen provozierten Massnehme auf uns zu überwälzen bestrebt sind, dazu zu zwingen, Farbe zu bekennen.

Tekst rozszyfrowanej depeszy, maszynopis.

Haus, - Hof und Staatsarchiv, Krieg, karton 1025, plik • (lfa), folio 4-14.

\section{Dokument nr 3}

1917 czerwiec 18, Baden. - Depesza nr 20533 przedstawiciela austro-węgierskiego Ministerstwa Spraw Zagranicznych Wilhelma Storcka w kwaterze głównej Naczelnej Komendy Armii dla ministra Ottokara Czernina o przeniessieniu $z$ Legionów Polskich do armii austro-węgierskiej tych Polaków, którzy byli obywatelami Austro-Wegier.

Das k.u.k. Armeeoberkommando hat mir im Einsichtswege von dem abschriftlich hier zuliegenden, am 14 leitenden Monats an Obersten von Paić und verschiedene andere militärische Stellen ergangenen Schreiben betreffend die Vorbereitungen für die Einrückung der polnischen Legionäre österreichischer und ungarischer Staatsangehörigkeit am 1 Juli dieses Monats Kenntnis geben. 
Auf meine Anfrage wurde mir von Oberst von Zeynek erläuternd mitgeteilt, dass die Durchführung der Einrïckungmachung unserer Legionäre, deren Vorbereitung selbstredend ein militärisches Dienstgeheimnis bilde, selbstverstädlich jederzeit annuliert oder abgeändert werden kann, falls vor dem erwähnten Termine eine andere Vereinbarung mit Deutschen Obersten Heeresleitung zu Stande käme resp.(?) die Legionäre auch weiterhin als Kaders oder sonst in Polen zu verbleiben hätten.

Auf das in Rede stehende Schreiben müsse vorerst eine Rückäusserung der mehrerwähnten militärischen Stellen (Chef des Ersatzwesens, k.u.k. Kriegsministerium und Landesverteidigungs - Ministerien) erfolgen, zu der vom Armeeoberkommando neuerlich Stellung zu nehmen sein wird. Die ganze Frage sie daher noch immer in keiner Weise präjudiziert.

Storck

Kopia rozszyfrowanej depeszy, maszynopis.

Haus, - Hof und Staatsarchiv, Krieg, PA I, karton 1025, plik $\alpha$, folio 27-31.

Depesza jest uzupełniona dwoma załącznikami:

- odpis pisma AOK nr 91330,

- odpis porozumienia między generałem von Beselerem a pułkownikiem Paićem (nr 62 470/P), który reprezentował austro-węgierską Naczelną Komendę Armii.

Załącznik nr 91330 otrzymali:

- Szef Uzupełnień Osobowych armii austro-węgierskiej,

- Ministerstwo Wojny Austro-Węgier w Wiedniu,

- Ministerstwo austriackiej Obrony Krajowej w Wiedniu,

- Ministerstwo węgierskiej Obrony Krajowej w Budapeszcie,

- Pułkownik Paić jako przedstawiciel Naczelnej Komendy Armii austro-węgierskiej w Warszawie przy generał-gubernatorze von Beselerze.

\section{Załącznik nr 1.}

Laut Vereinigung des Armee Oberkommando mit Deutsche Oberste Heeresleitung sind die im polnischen Hilfskorpa befindlichen östrreichischen un ungarischen Staatsbürger - imsgesamt 832 Offiziere und 11716 Unteroffiziere bezziehugsweise Mann (hievon 200 ungarische Staatsbürger) - bis zum 1 Juli leitendes Jahres aus der polnischen Armee auszuscheiden und der militärischen Dienstleistung in der österreichisch-ungarische Armee zuzufiihren.

Das AOK beantragt, diese Offiziere und Mannschaften Truppenkörpern, welche an der russischen Front eingeteilt sind zuzuweisen. 
Für die Durchführung der von deutschen General Gouverneur in Warschau zu bewirkenden Überstellung wären mehrere Orte in deutschen Sprachgebiete von Böhmen, Nieder - und Oberösterreich fürzuwählen, in die die Sammeltransporte der Legionäre zu leiten, dort mit tunlichster Beschleunigung zu mustern, aufzustellen und in die bestimmenden Ersatzökrper - Stationen abzuinstradieren wären.

Das AOK beehrt sich an den k.u.k. Chef des Ersatzwesens das dorthiesigen Ersuchen zu stellen, im Einvernehmen mit dem k.u.k. Kriegsministerium und k.k. Ministerium für Landes- verteidigung die Zielstationen für die aus dem Ggenaral Gouvernement Warschau kommenden Sammeltransporte der Legionäre ehesten fürzuwählen, die erforderlich Versorgen für Unterkunft und Verpflegung treffen zu lassen und das AOK hievon sowie vom Zeitpunkt, zu welchem mit dem Eintreffen der Transporte begonnen werden kann, sobald als möglich zu verständigen, damit der Abtransport je aber beginnen könne, da einerseits die Überstellung bis 1 Juli beendet sein muss, anderseits nicht auf einen $\mathrm{z} u$ kurzen Zeitraum zusammengedrängt werden soll.

Załącznik nr 2 do depeszy; numer kancelaryjny załącznika 62 470/P

Vereinbarungen

Zwischen dem Generalgouverneur von Warschau und Oberst von Paić. Betreffen: Übergabe des polnischen Hilskorps.

1. Das polnische Hilfskorps wird unverzüglich dem Generalgouverneur in Warschau General der Infanterie von Beseler übergeben, um im Sinne der vereinbarungen der beiden Obersten Heeresleitungen als Stämme für das aufzustellende polnische Heer zu dienen.

2. Das polnische Hilfskorps bildet zunächst - in seiner gegenwärtigen $\mathrm{Zu-}$ sammensetzung - den Kader polnischen Armee. Das Ausscheiden der östrreichischen und ungarischen Staats-angehörigen aus dem polnischen Heere ist bis 1 Juli 1917 durchzuführen.

\section{Dokument nr 4}

1917 czerwiec 19, Warszawa. - Depesza nr 6229 przedstawiciela austro-węgierskiej Naczelnej Komendy Armii putkownika Jozefa Paića do austro-wegierskiego ministra spraw zagranicznych Ottokara Czernina o pisemnej 
propozycji generata Beselera w sprawie wydzielenia z Legionów Polskich osób majacych obywatelstwo austriackie i węgierskie.

Vom Generalgouverneur von Beseler erhielt ich heute nachstehende $\mathrm{Zu}$ schrift.

„Die Verzögerung der die Bildung des polnischen Heeres endgültig regelnden Vereinbarung zwischen den Monarchen der beiden verbïndeten Zentralmächte hat insofern eine ungünstige Lage geschaffen, als mangels einem hierauf gegrïndeten Werbeaufrufes des Staatsrates Freiwillige sich erst spät und in geringer Anzahl zum Eintritte in das Heer gemeldet haben. Ihre Ausbildung ist zur Zeitnoch nich so weit vorgeschritten, dass ihre Einstellung in die Regimenter erfolgen könnte. Wenn nun gemäss dem zwischen den beiden Heeresleitungen getroffenen Abkommen vom 7 April dieses Jahres die österreicischen und ungarischen Staatangehörigen am 1 Juli dieses Jahres aus dem polnischen Heere ausscheiden, so verlieren die Regimenter den grösseren Teil ihres Bestandes, der zur Zeit noch nicht annährend ersetzt werden kann. Dieser Umstand veranlasst mich, nach Rïcksprache mit der Deutschen Obersten Heeresleitung, Euer Hochwohlgeboren zu ersuchen, das Einverständnis Ihres Armeeoberkommandos dazu herbeizuführen, dass die österreichischen und ungarischen Heeresangehörigen - in ihrer Gesamtheit - erst dann aus den polnischen Legionen herausgezogen werden sollen, wenn ihr Ersatz durch eine genügende Zahl ausgebildeter Rekruten gewährleistet ist. Diesen Zeitpunkt werde ich, sobald er sich mit Bestimmtheit voraussehen lässt, mitteilen".

Personlich füge ich bei, dass diese Massnahme unbedingt notwendig erschien, um täglich schwieriger werdende Situation zu retten ${ }^{1}$. Keine Ablehnung unserseits ist wohl ausgeschlossen aus Grïnden sachlicher Natur und im speziellen Interesse der Monarchie.

Erbitte eheste telegrafische Entscheidung.

Geht gleichlautend an Armeeoberkommando und direkte an Ministerium des Äussern.

Oberst Paić2

Kopia rozszyf rowanej depeszy, maszynopis.

Haus, - Hof und Staatsarchiv, Krieg, PA I, karton 1025, plik $\alpha$, folio 33-34.

1 Kopia zawiera osobistą uwagę pułkownika Paića, że wstrzymanie procesu wydzielania obywateli austriackich i węgierskich z Legionów Polskich jest uzasadnione austriacką racją stanu. 
2 Przedruk pisma sformułowanego przez generała von Beselera, ale bez uwag osobistych pułkownika Paića otrzymał także baron Lago, który przebywał w kwaterze głównej dowództwa armii austro-węgierskiej. Por. dokument nr 6232, folio 40-41.

\section{Dokument nr 5}

1917 czerwiec 19, Wiedeń. - Koncept pisma przygotowanego przez austro-węierskiego ministra spraw zagranicznych Ottokara Czernina do przedstawiciela tegoż ministerstwa Wilhelma von Storcka przy austro-węierskiej Naczelnej Komendzie Armii o odroczeniu procesu wydzielania z Legionów Polskich osób mających obywatelstwo austriackie i węgierskie.

Euer Hochwohlgeboren wollen dem Herrn Chef des Generalstabes mit Bezug auf sein Telegramm von heute, No 53 geheim, mitteilen, dass ich den Vorschlag der Deutschen Obersten Heeresleitung, demzufolge die österreichischen und ungarischen Heeresangehörigen - in ihrer Gesamtheit erst dann aus den polnischen Legionen heranzugezogen werden sollen, wenn ihr Ersatz durch eine genügende Zahl ausgebildeter Rekruten gewährleistet ist. als eine voläufige Lösung der polnischen Heeresfrage im Sinne meiner gestrigen Telefondepesche ansehe, und infolgedessen von meinem Standpunkte aus dem deutschen Antrage zustimmen. ${ }^{\text {? }}$

Koncept pisma, maszynopis.

Haus, - Hof und Staatsarchiv, Krieg, PA I, karton 1025, plik «, folio 32.

i Wilhelm von Storck miał przekazać pismo ministra szefowi austro-węgierskiego Sztabu Generalnego.

\section{Dokument nr 6}

1917 czerwiec 19, Warszawa. - Telegram nr 6232 barona Lago przebywajacego $w$ warszawskim przedstawicielstwie austro-wegierskiego Ministerstwa Spraw Zagranicznych do ministra Ottokara Czernina $z$ pismem generata von Beselera w sprawie odroczenia procesu wydzielania z Legionów Polskich osób majacych obywatelstwo austriackie $i$ wegierskie. 
General von Beseler hat an Oberst von Paić soeben nachfolgende Anschrift gerichtet: 1

Tekst odszyf rowanej depeszy, maszynopis.

Haus, - Hof und Staatsarchiv, Krieg, PA I, karton 1025, plik $\alpha$, folio 40-41.

1 Dalsza część tekstu por. dokument nr 4.

\section{Dokument nr 7}

1917 czerwiec 20. - Koncept pisma przygotowanego przez austro-wegierskiego ministra spraw zagranicznych Ottokara Czernina dla przedstawicieli tegoż ministerstía $w$ Warszawie $i$ Lublinie o zgodzie na odroczenie procesu wydzielania z Legionów Polskich osób majacych austriackie $i$ węgierskie obywatelstwo.

1.

Zum Telegramm vom 19 dieses Monats, Nr 394.

Wie Euer Hochwohlgeboren bekannt, habe ich vor einigen Tagen der kaiserlich deutschen Regierung dringend nahegelegt, auf den Plan, die östrreichischen Staatsangehörigen bis zum 1 Juli aus der polnischen Armee herauszuziehen, $z u$ verzichten, wenn tatsächlich, wie aus allen polnischen Informationen geschlossen werden musste, das Werk der polnischen Heeresbildung ernstlich gefährdet wïrde.

Der von Baron Lago einberichtete im Einvernehmen mit der Deutschen Obersten Heeresleitung abgefasste Vorschlag des Generals von Beseler trägt den von mir hervorgehobenen Gesichtspunkten Rechnung und ist somit als eine wenigstens vorläufige Lösung der polnischen Heeresfrage aufzufassen. In diesem Sinne habe ich meine Zustimmung zum Antrage des Warschauer Generalgouverneurs erteilt.

Den polnischen Politikern wollen Euer Hochwohlgeboren zu verstehen geben, dass sie unseren neuerlichen Bemühungen um das Gelingen der polnischen Heeresbildung die Erfüllung ihres dringenden Wunsches nach Belassung der ganzen ehemaligen Legion im polnischen Heer zu verdanken haben. Angesichts der tatsächlichen Verhältnisse in Polen und der grossen Schwierigkeiten, auf welche die Heeresbildung durch die Deutschen stösst, dïfte iibrigens der Ersatz der die Mehrheit im polnischen Heere ausmachenden 
österreichischen Staatsangehörigen durch ausgebildete Rekruten aus dem Königreiche lange auf sich warten lassen, so dass aus der provisorischen Lösung im Sinne der polnischen Wünsche möglicherweise eine für die dauer des Krieges definitive werden könnte.

Mit Bezug auf mein Euer Hochwohlgeboren mitgeteiltes Telegramm an Grafen Larisch de dato 17 Juni, Nr 397.

Baron Lago telegraphiert anher wie folgt:

"General von Beseler hat an Oberst Paić soeben nachfolgende Zuschrift gerichtet: ${ }^{1}$

[...] Ich habe hierauf an Herrn von Ugron die nachstehende telegraphische Weisung gerichtet: "(Inseratur aus Telegramm sub 1 von »Wie Euer Hochwohlgeboren bekannt, habe ich vor einigen Tage... " bis zum Schluss)"

Koncept pisma, maszynopis.

Haus, - Hof und Staatsarchiv, Krieg, PA I, karton 1025, plik $\alpha$, folio 35-38.

1 Dalsza część tekstu por. dokument n 4.

\section{Dokument nr 8}

1917 lipiec 13, Warszawa. - Telegram nr 446 przedstawiciela austro-węgierskiego Ministerstwa Spraw Zagranicznych Stefana Ugrona do ministra Ottokara Czernina o postanowieniu niemieckiego Naczelnego Dowództwa dotyczqcym wystania trzech putków legionowych na front.

Deutsche Heeresleitung hatte angeordnet, dass eine Brigade Legionstruppen (Infanterie-regimenter $\mathrm{Nr} 2$ und 3, Kavallerieregiment $\mathrm{Nr}$ 2) übermorgen an die russische Front abgeht.

Staatsrat nimmt dagegen Stellung, da dadurch Idee, das Legionen Kader der ponischen Armee bilden, aufgegeben wird. General von Beseler hält einstweilen an Anordnung fest. Nachricht hat tiefen Eindruck gemacht.

Odpis rozszyfrowanego telegramu, maszynopis.

Haus, - Hof und Staatsarchiv, Krieg, PA I, karton 1025, plik $\alpha$, folio 44. 


\section{Dokument nr 9}

1917 lipiec 13, Warszawa. - Telegram nr 447 jako depesza nawiazujaca do telegramu $n r 446 z$ informacja o wzburzeniu spowodowanym $w$ Warszawie po zapowiedzi dotyczacej wystania trzech oddziatów legionowych na front.

Aufregung in der Stadt sehr gross. Man befürchtet, dass die stark demoralisierten und von gewissenlosen Agitatoren bearbeiteten Legionstruppen sich weigern werden, an die Front zu gehen. Staatsrat vollkommen ratlos, da Vorstellungen bei Beseler resultatlos geblieben sind. Heute sollen in vertraulicher Sitzung Beschliisse iiber weiteres Verhalten gefasst werden.

Seitens des Staatsrates wurde ich halb-offoziell angegangen, dass ich in der Angelegenheit bei Beseler interveniere, was ich aber mit Rücksicht auf den militärischen Charakter der Frage dezidiert abgelehnt habe.

5 Infanterieregiment hat Eid ebenfalls verweigert.

Odpis rozszyf rowanego telegramu, maszynopis.

Haus, - Hof und Staatsarchiv, Krieg, PA I, karton 1025, plik $\alpha$, folio 43.

\section{Dokument nr 10}

1917 lipiec 14, Warszawa. - Telegram nr 449 przedstawiciela austro-wegierskiego Ministerstwa Spraw Zagranicznych w Warszawie Stefana Ugrona do ministra Ottokara Czernina o tymczasowym wstrzymaniu wysytki oddziatów legionowych na front.

Im Nachhange zu Telegram Nr 447.

Angesichts grosser allgemeiner Aufregung und der Stellungsnahme des Staatsrates hat General von Beseler beschlossen, derzeit von der Absendung der Legionen an die russische Front abzusehen.

Odpis rozszyf rowanego telegramu, maszynopis.

Haus, - Hof und Staatsarchiv, Krieg, PA I, karton 1025, plik $\alpha$, folio 42. 


\section{Dokument nr 11}

1917 lipiec 15, Warszawa. - Telegram nr 451 przedstawiciela austro-węgierskiego Ministerstwa Spraw Zagranicznych Stefana Ugrona do ministra Ottokara Czernina o nowym zamyśle niemieckich czynników wojskowych dotyczącym wydzielenia z Legionów Polskich sześciu tysięcy Galicjan i obawie, że ucierpi na tym prestiz Austro-Węgier.

Im Nachhange zu telegramm $\mathrm{Nr} 449$.

Abkommandierung einer geschlossenen Legionsbrigade auf russische Front ist zwar aufgehoben. Doch, wie Oberst Paić mir sagt, wird in Erwägung gezogen, 6000 galizischen Legionäre uns zur Kompletierung unserer Bestände zur Verfügung zu stellen.

Wenn auch solche hier militärisch derzeit entbehrt werden können, hätte ich grosse politische Bedanken gegen diesen Ausscheidung der Galizianer. Dieselbe würde schwerwiegende Konsequenzen haben und hier als Zeichen unserer völligen Erschöpfung ausgelegt werden, umsomehr, da deutscherseits systematisch verbreitet wird, dass wir uns in Galizien in einer äusserst bedrängten kritischen militärischen Lage befinden und auf die galizieschen Legionäre nicht weiter verzichten können. Der Gegensatz zwischen unserer und ihrer militärischen Kraft wird ganz offen hervorgehoben, um dadurch der Deutschen Macht stärker in Echeinung treten zu lassen und für sich Propaganda zu machen.

Odpis rozszyf rowanego telegramu, maszynopis. Haus, - Hof und Staatsarchiv, Krieg, PA I, karton 1025, plik $\alpha$, folio 45.

\section{Dokument nr 12}

1917 lipiec 16, Wiedeń. - Koncept depeszy nr 446 przygotowanej przez ministra Ottokara Czernina dla ambasadora księcia Gottfrieda zu Hohenlohe $w$ Berlinie oraz Wilhelma Storcka w kwaterze gtównej Naczelnej Komendy Armii o przypuszczalnych niekorzystnych następstwach wydzielenia Galicjan $z$ Legionów Polskich; w nawiazaniu do telegramu Stefana Ugrona nr 449. Front..."1

"Abkommedierung einer geschlossenen Legionsbrigade auf russische 
Ich nehme an, dass die auf die 6000 galizischen Legionäre bezügliche Nachricht Herrn von Ugrons auf einem Missverständnisse beruht. Eine solche Massnahme stünde nämlich im Wiederspruche mit dem auf Vorschlag der deutschen Obersten Heeresleitung zwischen dieser und dem Armee-Oberkommando im Einvernehmen mit küzlich getroffenen Kompromisse, wonach die österreichischen und ungarischen Heeresangehörigen in ihrer Gesamtheit erst dann aus den polnischen Legionen herausgezogen werden, wenn ihr Ersatz durch eine genïgende Zahl ausgebildeter Rekruten gewährleistet ist.

Abgesehen hievon, bin ich der Ansicht, dass es nur zur Verschärfung der ohnehin sehr bedenklichen Legionskrise beitragen könnte, wenn die Ausscheidung der Galizianer in dieser neuen Form wieder zur Erorterung gelangen wiirde. Es ist meiner Ansicht nach ein gemeinsames Interesse Deutschlands und Österreich-Ungarns, die Legionskrise mit grösster Vorsicht zu behandeln und möglichst eine Wendung zu vermeiden, welche zur gänzlichen Auflösung der Legionen und in weiterer Folge zum Scheitern unserer gemeinsamen militärischen und politischen Ziele in Polen führen könnte.

Ich ersuche Euer Durchlaucht, sich an massgebender Stelle unter teilweiser Verwendung des Telegrammes Herrn Ugrons im obigen Sinne zu äussern und den Standpunkt der dortigen Regierung anher ehestens mitzuteilen.

Für Baron Arz.

Ich richte an den k.u.k. Botschafter in Berlin nachstehendes Telegramm ${ }^{2}$.

Ich glaube annehmen zu können, dass Euer Exzellenz in Bezug auf die Inopportunität der Ausscheidung der 6000 galizischen Legionäre meiner Auffassung zustimmen. In diesen Falle wäre es vielleicht zweckmässig, wenn Euer Exzellenz den Vertreter des Armee-Oberkommandos bei der deutschen Obersten Heeresleitung beauftragen wollen, sich dieser gegenuiber in einem der Instruktion an den k.u.k. Botschafter in Berlin ähnlichen Sinne zu äussern.

Koncept pism przeznaczonych do zaszyfrowania, maszynopis. Haus, - Hof und Staatsarchiv, Krieg, PA I, karton 1025, plik $\alpha$, folio 46-49

1 Dalej tekst jak w dokumencie nr 12.

2 Dalej tekst jak w. części pierwszej tego dokumentu, przeznaczonej dla ambasadora w Berlinie. 


\section{Dokument nr 13}

1917 lipiec 18, Berlin. - Telegram nr 481 ambasadora księcia Gottfrieda zu Hohenlohe do ministra Ottokara Czernina $z$ informacja, ze niemiecki Urzqd Spraw Zagranicznych podziela negatywne stanowisko Austro-Wegier $w$ sprawie dotyczqcej wydzielenia 6000 legionistów do dyspozycji Austro-Węgier.

Auwertiges Amt, dern iiber die beabsichtigte Ausscheidung von 6000 galizischen Legionären zum Kompletierung unserer Bestände bisher nichts bekannt ist, teilt Auffassung Euer Exzellenz, wonach eine solche Massnahme mit den zwischen den beiden Regierungen und den Obersten Heeresleitungen getroffenen vereinbarungen im Wiederspruche stünde.

Hiesiger Referent für Polen, Prinz Hatzfeldt, begibt sich in den allernächsten Tagen nach Warschau, wo er mit General von Beseler auch diese Frage besprechen wird.

Tekst rozszyfrowanego telegramu, maszynopis.

Haus, - Hof und Staatsarchiv, Krieg, PA I, karton 1025, plik $\alpha$, folio 50.

\section{Dokument nr 14}

1917 lipiec 20, Baden. - Pismo nr 21400 Wilhelma Storcka do ministra Ottokara Czernina w sprawie ewentualnego wydzieleni z Legionów Polskich 6000 osób majqcych obywatelstwo austriackie i węgierskie.

Ich habe seinerzeit Euer Exzellenz die Korrespondenz General Ludendorffs mit General Baron Arz betreffend die zur Verfügungstellung von 6000 österreichischen und ungarischen Legionären ergebenst gemeldet (mein Bericht vom 16 leitendes Monats Nr 21321 ).

Auf die Erwiderung Baron Arz, in der dieser gegen die deutscherseits beabsichtigte Ausscheidung von 6000 unserer Legionäre bekantlich Stellung genommen hat, ist seitens General Ludendorffs nunmehr die in der Anlage abschriftlich mitfolgende Antwort eingelangt. Deutsche Oberste Heeresleitung verweist in ihr auf die Eidesverweigerungen der Legionäre und die Unmöglichkeit, nach diesen Vorkommnissen das polnische Hilfskorps als solches bei der Ober-Ost militärisch zu verwenden. Gleichzeitig wird die Aufstellung des polnischen Heeres nunmehr auch deutscherseits nur mehr 
als eine politische Massnahme qualifiziert, die gegenüber der militärischen Notwendigkeit, unsere Truppenstände in Galizien zu verstärken, in den Hintergrund $\mathrm{zu}$ treten hätte.

Baron Arz, von rein militärischen Konsiderationen geleitet, hat aus dieser Antwort gewisse Schliisse gezogen, die er Euer Exzellenz durch Oberst von Zeynek mündlich bakannt geben lassen wollte. Angesichts der Dringlichkeit der Angelegenheit ersuche er mich aber nunmehr, seine Ausführungen Euer Exzellenz schriftlich einzuberichten. Die Abschrift der gegenständlichen, an mich gerichteten Note liegt sub „B” bei. ${ }^{1}$

Storck

Tekst rozszyfrowanego telegramu, maszynopis.

Haus, - Hof und Staatsarchiv, Krieg, PA I, karțon 1025, plik $\alpha$, folio 52-58.

1 Do pisma Wilhelm Storck dodał dwa załączniki. W załączniku „B” występuje nazwisko barona Konopki. Chodzi o Jana Konopkę, który był austro-węgierskim komisarzem rządowym przy Tymczasowej Radzie Stanu w Królestwie Polskim.

\section{Załącznik "A"}

Abschrift eines Telegrammes des Generals Ludendorff an General von Cramon für General Baron Arz vom 18 Juli 1917, Nr 21167 P.

Wie ich Euer Exzellenz mit I a 3899 geh. Op. vom 11 Juli auszufïhren mir erlaubte, ist eine Verstärkung in Galizien unbedingt nötig, Deutschland aber nicht.in der Lage, die nach Osten abgegebenen Kräfte, die zur Zeit zum Teil als Ersatz der bei k.u.k. 3 in 2 Arme eingetretenen Ausfälle eingesetzt sind, dort dauernd zu belassen. Eine Zuweisung von Kräften von der Süidwestfront haben Euer Exzellenz als ausgeschlossen erklärt. Eine Schwächung der Siebenbürger und rumänischen Front halte ich bei den zweifellos bestehenden Angriffsabsichten der Russen und Rumänen für unmöglich. Nun hat sich auch die mit Euer Exzellenz Einverständnis (dortige Nr $42860 \mathrm{Op}$ ) befohlene Verwendung geschlossener Truppenteile des polnischen Hilfskorps bei Ober-Ost nach Meldung des Generalgouverneurs Warschau infolge der bei und nach der Eidesleistung des Hilfskorps bewiesenen Haltung als unausführbar herausgestellt, und zwar so, dass auf eine militärische Verwendung des polnischen Hilfskorps edngïltig nicht mehr gerechnet werden kann und es sich bei der Aufstellung des polnischen Heeres 
jetzt nur noch um eine rein politische Massnahme handelt. Ich habe daraufhin, im Sinne vom I a 3399 Op., um Euer Exzellenz zu unterstiitzen, den Generalgouverneur in Warschau gefragt, wieviele k.u.k. Mannschaften er der k.u.k. Obersten Heeresleitung zur Auffüllung der geschwechten k.u.k. Truppen in Galizien unter Zurïckstellung aller sonstigen Bedenken zur Verfügung stellen könnte. Mein Fernschreiben 21102 P enthält die Antwort.

Ich glaube, Euer Exzellenz Zustimmung sicher zu sein, dass politische Rücksichten den militärischen Notwendigkeiten gegenüber zurücktreten müssen, und bitte dringend, baldigst der beabsichtigten Massnahme zuzustimmen und dem Generalgouverneur Warschau Weisung betreff Ziel der Transporte zukommen zu lassen.

Nr 21167 P. I A Ludendorff.

\section{Załącznik „B”}

K.u.K. Armeeoberkommando

Nr $131831 /$ P.

Chef des Generastabes.

An

Den Vertreter des k.u.k. Ministeriums des Äussern beim AOK Stand ort des AOK, am 20 Juli 1917

Ich ersuche Euer Hochwohlgeboren, Nachstehendes Seiner Exzellenz Grafen Czernin ehestens mitteilen zu wollen.

Da die von mir angeregte mündliche Berichterstattung nicht rechtzeitig möglich ist, beehre ich mich, Euer Exzellenz folgendes mittzuteilen.

Die Deutsche Oberste Heeresleitung beantwortete meine, Euer Exzellenz auch zugekommene Depesche MV Nr $131110 / \mathrm{P}^{1}$ dahin, dass auf eine militärische Verwendung des polnischen Hilfskorps infolge der bei und nach der Eidesleistung an den Tag getretenen Unverlässigkeit desselben endgiltig nicht mehr gerechnet werden kann und es sich bei Aufstellung des polnischen Heeres jetzt nur noch um eine rein politische Massnahme handelt.

Gleichzeitig wiederholte die Deutsche Oberste Heerseleitung das Ersuchen, die vom Generalgouverneur in Warschau zur Verfïgung gestellten 6000 österreichischen und ungarischen Staatsbürger aus den Legionen zur notwendigen Verstärkung österreichisch-ungarischen Truppen in Galizien zu übernehmen.

Ich beehre mich Euer Exzellenz meine Auffassung vom rein militärischen Standpunkte dahin mitzuteilen, dass das polnische Hilfskorps auf Grund 
der von der Deutsche Oberste Heeresleitung angeführten Verhältnisse weder als Kader der polnischen Armee noch als geschlossene Einheit nilitärisch brauchbar ist, dass es daher vom militärischen Standpunkte aus gerechtfertig wäre, das polnische Hilfskorps aufzulösen. Die von Deutsche Oberste Heeresleitung beatragte Massregel ist einer solchen Auflösung gleichzuhalten, da nach den Abzug von 6000 Österreichern und der bereits in Kriegsgefangenenlager abgeschobenen 3000 Eidverweigerer nur noch circa 3000 Mann verbleiben wïrden. Eine Ablehnung dieser militärisch berechtigten Forderung der Deutscher Obersten Heeresleitung würde naturgemäss die weiteren Verhandlungen mit der Deutsche Oberste Heeresleitung bezïglich Polen und Rumänien erschweren. Auch bitet die weitere Belassung der österreichischen und ungarischen Staatsagehörigen in dem polnischen Hilfskorps die Grundlage zu untererbrochenen Differenzen militärisch-organisatorischer Natur (Fragen der Staatsangehörigkeit, des Idee, des Gerichtswesens) und zwar nicht nur gegeniiber den Deutschen, sondern auch gegeniiber den Polen. Ich müsste also vom Militärischen Standpunkte der beantragten Massregel zustimmen, allerdings mit der Modifikation, dass nicht nur die angebotenen 6000 Mann, sondern das gesamte österreichisch-ungarische Personal und Material uns zurückgegeben werde, eine Massregel, die für uns militärisch positiven Wert hätte. Ich bin mir aber dessen bewusst, das diese Massnahme in erster Linie vom Gesischtspunkte der in Polen zu verfolgenden politischen Ziele beurteilt werden muss, und erbitte mir aber die umgehende Bekanntgabe der Stellungsnahme Euer Exzellenz.

Ich bemerke hiebei, dass ein direkter Widerspruch zwischen den Erklärungen der Deutsche Oberste Heeresleitung und dem Verhalten des Generalgouverneurs von Warschau besteht, welcher nach dem Berichte Res. Nr 358 des Baron Konopka den Beschlüssen des Staatsrates vom 15 Juli bezïglich seiner Ingerenz auf die Legionen und die Verwertung derselben zugestimmt hat.

Ich beehre mich weiters darauf hinweisen, dass nach der eingangs zitierten Mitteilung der Deutschen Obersten Heererasleitung die Auffstellung einer polnischen Armee von deutscher Seite nicht mehr als militärische, sondern jetzt nur noch als rein politische Massnahme betrachtet wird, Es treffen also die Voraussetzungen, welche für das Monarchenabkommen bestimmend waren, nicht mehr zu und es erschiene mir von militärischen Standpunkte angezeigt, dass wir unter diesen Verhältnissen uns an dieser Aktion militärisch iiberhaupt nicht beteiligen, also das Ausbildungs - und Führer -Personal zurïckziehen. Dies würde allerdings zunächst eine diesbezügliche Erklärung des Generalgouverneurs von Warschau notwendig machen. 
Auch in dieser Frage werde ich meine Stellungsnahme von den politischen Absichten Euer Exzellenz abhängig machen.

Ich beehre mich schliesslich, auf den Bericht Res. Nr 358 vom 16 Juli leitendes Jahres des Baron Konopka hinzuweisen. Laut welchem der Generalgouverneur von Warschau dem Staatsrate weitestgehende Befugnisse gegenüber der polnischen Armee zuzugestehen scheint. In dieser Hinsicht muss ich betonen, dass die Schaffung einer polnischen Armee unter polnischen Leitung absolut unzulässig wäre, da durch Polen die wichtigsten Nachschublinien unserer Armee führen, die Bildung militärisch nicht unbedingt verlässlicher Kräfte in Polen dahin nicht zugelassen werden darf.

\section{Dokument nr 15}

1917 lipiec 23, Wiedeń. - Depesza ministra Ottokara Czernina do szefa austro-węgierskiego Sztabu Generalnego generata Artura Arza w sprawie dotyczacej wydzielenia z Legionów Polskich 6000 osób majacych obywatelstwo austriackie $i$ wegierskie.

Euer Exzellenz Note vom 20 dieses Monats Nr 131 231/P., mit.welcher es Hochdenselben gefällig war, den Standpunkt der Deutschen Obersten Heeresleitung in der Frage Abtransportes der 6000 Legionäre österreichischer (ungarische) Staatsangehörigkeit mitzuteilen, habe ich zu erhalten die Ehre gahabt.

Mit meiner an Legationsrat von Storck gerichteten Telephondepesche vom 17 dieses Monats habe ich mir bereits erlaubt, meine Einwendungen und Bedanken gegen diese seitens der Deutschen Obersten Heeresleitung geplante Massnahme zu Euer Exzellenz Kenntnis zubringen.

Meine damals in erster Linie erhobene Einwendung, wonach diese Massnahme in direktem Wiederspruche stünde mit der auf Vorschlag der Deutschen Obersten Heeresleitung zwischen den beiden Heeresleitungen getroffenen Abmachung ïber den Verbleib unserer Nationalen in der polnischen Armee, wurde seither seitens des deutschen Auswertigen Amtes dem Botschafter Prinzen Hohenlohe gegenïber, der von mir beauftragt war, in dieser Frage bei der deutschen Regierung vorstellig zu werden, rückhaltslos anerkannt. Zugleich hat das Auswärtige Amt in Berlin unseren Botschafter gegenüber die Absicht geäussert, die Angelegenheit bei General von Beseler in diesem Sinne zur Sprache bringen zu wollen. 
Was nun meine ïbrigen Bedenken gegen die Ausscheidung der 6000 Österreichischer (Ungarn) durch deren Abschiebung an unsere Front betrifft, so bin ich nach wie vor der Ansicht gut zu machender politischen Fehler wäre.

Nach der gegenwärtigen Lage in Warschau kann nämlich mit ziemlicher Sicherheit vorausgesehen werden, dass die Abtranspotierung unserer 6000 Legionäre die Stellung des Staatsrates im Lande vollkommen untergraben, unsere im Zuge befindliche Aktion zur Errichtung von polnischen Staatsbehörden mit einem Schlage zunichte mache und die Realisierung der Idee einer polnischen Armeebildung an Seite der Zentralmächte endgiltig ausser den Bereich jedweder Möglichkeit rücken würde.

Nach dem vorliegenden Informationen und Nachrichten scheint der provisorische Staatsrat den besten Willen zu haben, den Kampf gegen die radikal-republikanischen Wühlereien, auf welche die Legionskrise allein zurückzuführen ist, aufzunehmen. Wir sollen meiner Ansicht nach daher die Hoffnung nicht aufgeben, dass gelingen wird, die Legionskrise ins Geleise zu bringen, falls wir selbst den Staatsrat stiitzen und durch kluge und vorsichtige Behandlung dieses schwierigen Problems seine Bemühungen erleichtern.

Ich stimme vollkommen dar von Euer Exzellenz angedeuteten Ansicht zu, dass die von der Deutschen Obersten Heeresleitung in Ansicht genommene Abschiebung der 6000 Legionäre, besonders im Hinblick auf den mit Zustimmung Generals von Beseler am 18 dieses Monats veröffentlichten Aufruf des Staatsrates über seine Stellung zu den Legionen, eine sehr schwere und - meiner Ansicht nach - den Bestand des Staatsrates unbedingt gefährdende Komplikation bedueten würde.

Die Betrachtung, wonach der Vrbleib unserer Staatsangehörigen in den Legionen auch wegen der Gerichtsbarkeitsfrage eine Quelle fortwährender Reibereien und Schwierigkeiten sei, dürfte wohl durch die mittlerweile erfolgte Unterstellung unserer Nationalen unter das deutsch-polnische Militärstrafrecht gegenstandslos geworden sein.

Zusammenfassend glaube ich kaum, dass der militärische Nutzen, der uns aus dem Zuwachs von 6000 Mann, deren Wert und Verläslichkeit mir ïbrigens bei ihrer momentanen Stimmung zumindest zweifelhaft erscheint, jene schweren politischen Nachteile aufzuwiegen vermöchte, welche uns und Deutschland aus der von der Deutschen Obersten Heeresleitung beantrachten Massnnehme sowohl in Polen wie auch in ganzen feindlichen und neutralen Auslande zweifellos erwachsen würden.

Insbesondere möchte ich letzterer Baziehung davon warnen, die zu erwartende Wirkung unserer in günstiger Entwicklung begriffenen Offensive 
in Galizien auf die Feinde und Neutralen durch einen iibereilten Schritt, welcher das vollkommene Scheitern der auf dem Akte vom 5 November basierten Politik Österreich-Ungarns und Deutschalands zur Folge haben kann, auf politischen Gebiete zu paralysieren.

Falls, wie ich annehmen zu können glaube, Euer Exzellenz meine oben dargelegten Ansichten teilen, wïrde ich Hochdieselben bitten, der Deutschen Obersten Heeresleitung eine Anwort in diesem Sinne erteilen zu wollen.

Ich beauftrage unter einem den k.u.k. Botschafter in Berlin, bei der kaiserlichen Regierung, in ähnlichen Sinne vorstellig zu werden.

Koncept telefonicznej depeszy, maszynopis.

Haus, - Hof und Staatsarchiv, Krieg, PA I, karton 1025, plik $\alpha$, folio 59-64.

\section{Dokument $\mathrm{nr} 16$}

1917 lipiec 24, Warszawa. - Telegram nr 474 warszawskiego przedstawiciela Austro-Weggier do ministra Ottokara Czernina o wzburzeniu w Legionach Polskich $w$ zwiqzzu z aresztowaniem Józefa Piłsudskiego.

In den Legionen besteht eine auch von den Konservativen unterstiitze Bewegung, dass alle Galizianer als Protest gegen Vehaftung Piłsudskis Austritt anstreben und sich freiwllig zum Eintritt in die k.u.k. Armee melden sollen.

Ich wurde gefragt, ob dieselben in diesem Falle wohl in ihrer entsprechendes Regiment eingereiht, oder ob ein besonderer polnischer Truppenkörper gebildet wurden würde.

Ich erklärte, diesbezüglich nicht orientiert zu sein, aber anzunehmen, dass freiwillig sich Meldende in die verschiedenen galizischen Regimenter, wohin sie gehören, eingereiht werden, da ich nicht glaube, dass, nach dem hier eine polnische Armee entstehen soll, wir eine solche provisorisch bei uns bilden wiirden.

Diese Antwort scheint nicht befriedgt $z u$ haben und wird hoffentlich den momentan politisch nicht erwïnschten Massenaustritt der Galizianer aus den Legionen hintanhalten oder wenigstens reduzieren.

Odpis rozszyf rowanej depeszy, maszynopis.

Haus, - - Hof und Staatsarchiv, Krieg, PA I, karton 1025, plik $\beta$ (eta), folio 81. 


\section{Dokument nr 17}

1917 lipiec 26, Wiedeń. - Koncept depeszy nr 475 ministra Ottokara Czernina do szefa Sztabu Generalnego barona Artura Arza i księcia Gottfrieda zu Hohenlohe $w$ sprawie zamystów dotyczqcych wydzielenia z Legionów Polskich 6000 obywateli austriackich i węgierskich.

Polnische Legion, Herausziehung der 6000 Österreicher (Ungarn).

$\mathrm{Zu}$ Euer Exzellenz persönlichen Informationen beehre ich mich mitzuteilen, dass Seine Majestät ïber einen von mir auf telephonischem Wege erstatteten Vortrag dahin entschieden haben, dass in der Frage der polnischen Legionen vorläufig keine Verfügung getroffen werde, bis anlässlich des bevorstehenden Besuches des Deutschen Reichskanzlers in Wien Gelegenheit gefunden wird, mit Letzterem den ganzen Komplex der polnischen Frage eingehend durchzusprechen.

$\mathrm{Zu}$ meinen Telegramm Nr 464 und Nr 467 vom 23 beziehungsweise 24 dieses Monats.

Streng vertraulich.

Seine k.u.k. Apostolische Majestät haben anzuordnen geruht, dass in der Frage der polnischen Legionen vorläufig keine Verfïgung getroffen werde, bis anlässlich des bevorstehenden Besuches des Deutschen Reichkanzlers in Wien Gelegenheit gefunden wird, mit Letzterem den ganzen Komplex der polnischen Frage eingehend durchzusprechen.

Vorstehendes zu Euer Durchlaucht streng vertraulichen Information. ${ }^{1}$

Koncept depesz z identycznym tekstem, maszynopis.

Haus, - Hof und Staatsarchiv, Krieg, PA I, karton 1025, plik $\alpha$, folio 65-66.

1 Egzemplarz depeszy przeznaczonej dla barona Artura Arza został skierowany za pośrednictwem Wilhelma Storcka.

\section{Dokument nr 18}

1917 lipiec 26, Baden. - Depesza nr 21565 Wilhelma Storcka do ministra Ottokara Czernina o zamiarze odwotania przez szefa austro-węgierskiego Sztabu Generalnego obywateli Austro-Węgier z Legionów Polskich.

Bezug auf Euer Exzellenz Telephondepesche von heute. 
Exzellenz Baron Arz ersucht mich um Weiterleitung nachstehender Depesche an Euer Exzellenz.

"Ich danke ergebenst für die Mitteilung bezüglich der Polenfrage. A us militärischen R̈̈̈cksichten muss ich auf der Heranziehung der österreichisch-ungarischen Staatsangehörigen der polnischen Legion bestehen, da ich durch deren Einsatz eine dringend benötigte Infaneriedivision freimachen kann. Graf Szeptycki hat sich für die Heranziehung dieser Staatsangehörigen ausgesprochen.

Für eine gefällige Mitteilung, wann der Besuch des deutschen Reichskanzlers, somit auch die Lösung der Legionenfrage zu erwarten ist, wäre ich Euer Exzellenz sehr verbunden"

Tekst otrzymanej depeszy, maszynopis.

Haus, - Hof und Staatsarchiv, Krieg, PA I, plik $\alpha$, folio 67 .

\section{Dokument nr 19}

1917 sierpień 1, Wiedeń. - Koncept depeszy ministra Ottokara Czernina do barona Artura Arza z powiadomieniem o poinformowaniu kanclerza Georga Michaelisa, ze sprawa wydzielenia 6000 obywateli Austro-Wegier z Legionów Polskich wymaga rozwagi oraz skierowania wydzielonych tylko na lubelski obszar okupacyjny.

In der Frage der von der Deutschen Obersten Heeresleitung verlangten und vom Reichskanzler Michaelis heute hier vorgebrachten Herausziehung de 6000 österreichischen (ungarischen) Legionäre und ihrer Entsendung an die galizisch - russischen Front, habe ich nach Darlegung der politischen Grïnde, aus welchen uns diese Masregel in hohen Grade bedenklich erschiene, als Ausweg den Gedanken zur Diskussion gestellt, diese 6000 Legionäre als geschlossenen Truppenkörper nach dem Generalgouvernement Lublin, also innerhalb des Königreiches Polen zu beordern und an deren Stelle eine gleiche Anzahl österreichisch-ungarischer Truppen aus dem gedachten Generalgouvernement an die ga.lizisch-russischen Front zu entsenden.

Ich ersuche Euer Exzellenz dringend mich wissen zu lassen, welchen Standpunkt Hochdieselben gegenïber diesen Gedanken einnehmen, um die bezïglichen Besprechungen mit dem Herrn Reichskanzler noch heute fortsetzen zu können. 
Koncept depeszy, maszynopis.

Haus, - Hof und Staatsarchiv, Krieg, PA I, karton 1025, plik $\alpha, 68-69$.

\section{Dokument nr 20}

1917 sierpień 1, Baden. - Depesza telefoniczna nr 21785 Wilhelma Storcka z odpowiedziq barona Artura Arza w sprawie wydzielenia z Legionów Polskich 6000 obywateli Austro-Węgier na obszar lubelskiego generat-gubernatorstwa.

Bezug auf Euer Exzellenz Telephondepesche von heute betreffend Herausziehung der 6000 österreichischen und ungarischen Legionäre.

In Beantwortung der Anfrage Euer Exzellenz ersucht mich Baron Arz um Weiterleitung nachstehender Depesche an Euer Exzellenz.

„Euer Exzellenz beehre ich mich ergebenst mitzuteilen, dass wir im Bereiche des Militärgouvernements Lublin keine Truppen haben. Es befinden sich dort nur Ersatzbataillone bezihungsweise Etappenbataillone. Die angeregte Lösung kann also nicht durchgeführt worden.

Die militärische Lage bedingt aber die Herauszihung der Legonäre galizischer Provrnienz.

Arz, General der Infanterie

Odpis odnotowanej depeszy, maszynopis.

Haus, - Hof und Staatsarchiv, Krieg, PA I, karton 1025, plik $\alpha$, folio 70.

\section{Dokument nr 21}

1917 sierpień 3, Wiedeń. - Koncept telegramu nr 490 ministra Ottokara Czernina do ambasadora księcia Gottfrieda zu Hohenlohe o wynikach rozmowy z kanclerzem Georgiem Michaelisem w sprawie wydzielenia z Legionów Polskich 6000 obywateli Austro-Węgier.

Ich hatte gestern abends noch eine etwas lebhafte Auseinandersetzung mit dem Herrn Reichskanzler, weil derselbe anscheinend nach telephonischer Rücksprache mit General Ludendorff erklärt, er kann nicht zugeben, 
dass 6000 andere Soldaten aus unserem Polen an die Front gingen, sondern müsse darauf bestehen, dass die 6000 Mann aus der polnischen Legion hiefür verwendet werden.

Dieser Standpunkt deckt offen auf, dass es sich der Deutschen Obersten Heeresleitung nicht um ein militärisches sondern ein politisches Manöver handelt.

Um bis an die äusserste Grenze des Entgegenkommens zu gehen, habe ich schliesslich erklärt, dass ich auch damit einverstanden bin, vorausgesetzt, dass es General von Beseler gelingt, den polnischen Staatsrat für diese Lösung zu gewinnen, da ich in diesem Falle die Erregung unserer Polen zu beschwichtigen hoffe.

Euer Durchlaucht wollen den weiteren Verlauf der Angelegenheit genauestens verfolgen und fortlaufend berichten.

Koncept telegramu, maszynopis.

Haus, --- Hof und Staatsarchiv, Krieg, PA I, karton 1025, plik $\alpha$, folio 71-72.

\section{Dokument nr 22}

1917 sierpień 4, Wiedeń. - Koncept telegramu ministra Ottokara Czernina do radcy dworu barona Marsovsky'ego o niekorzystnych przewidywaniach $w$ wyniku rozmowy premiera A ustrii z przedstawicielem niemieckiego naczelnego dowództwa generatem A ugustem von Cramonem $w$ sprawach Legionów Polskich.

Euer Wohlgeboren wollen sofort dem Herrn k.k. Ministerpräsidenten in meinem Namen folgendes mitteilen.

Den mir aus Warschau zugekommenen Meldungen zufolge bestätigt sich die Information, dass die polnische Offentlichkeit die Herausnahme der österrechischen Legionre aus dem polnischen Heer behufs Verwendung an der galizischen Front ruhig aufnehmen wïrde, nicht. Ich ersuche deshalb den Herrn Ministerpräsidenten, in einem etweigen Gespräche mit General von Cramon ïber die Legionsfrage keine günstige Prognose für den Fall der Abberufung der österreichischen Legionäre aus Warschau stellen, vielmehr auf die voraussichtich äusserst ungïnstigen Folgen eines solchen Schrittes auf den Fortgang des polnischen Staatsaufbaues hinweisen zu wollen.

Zur streng vertraulichen Kenntnis Herrn von Seidlers möchte ich nochbemerken, dass ich der kaiserlich deutschen Regierung gegenüber nach wie 
vor auf dem Standpunkte verharre, dass eine Herausziehung unserer Legionäre nur dann möglich sei, wenn der Warschauer Staatsrat hiezu seine Einwilligung gibt.

Koncept telegramu, maszynopis.

Haus, - Hof und Staatsarchiv, Krieg, PA I, karton, 1025, plik $\alpha$, folio 75-76.

\section{Dokument nr 23}

1917 sierpień 5. - Koncept telegramu ministra Ottokara Czernina do radcy dworu barona Marsovsky'ego o postulatach parlamentarnego Koła Polskiego w sprawach dotyczących Legionów Polskich i sprawy polskiej.

Das Präsidium des Polenklubs ersucht in bekannten Legionenfrage um folgendes.

I. General Arz möchte, bevor ein entscheindender Schritt geschieht, das Präsidium empfangen, womöglich in meiner Gegenwart. (Es handelt sich um gewisse militärische Fragen, so vor allem das Ersatzwesen).

II. Auf politischen Gebiete bitten die Polen, es möge der Regentschaftsrat und die bekannten Justiz-und Schulforderungen gleizeitig bewilligt werden.

Euer Hochwohlgeboren wollen Obiges dem Herrn Ministerpräsidenten und general Cramon mitteilen, jedoch beide ersuchen, kein fait accompli zu schaffen, bis wir uns nicht gesprochen haben.

Die Polen würden einem Ministerium Seidler bestimmt Opposition machen, wenn ïber ihre Köpfe vorgegangen wïrde; anderseits hoffe ich, auf die erwähnte Art. Die Legionenfrage im Sinne der beiden Heeresleitungen lösen zu können.

Czernin

Koncept telegramu, maszynopis.

Haus, - Hof und Staatsarchiv, Krieg, PA I, karton 1025, plik $\alpha$, folio 77-78. 


\section{Dokument nr 24}

1917 sierpień 5, Baden. - Pismo przewodnie Wilhelma Storcka do ministra Ottokara Czernina z czterema załacznikami.

\section{Seiner Exzellenz}

Dem Herrn Minister des kaiserlich und königliches Hauses Und des Äussern Ottokar Grafen Czernin

vorgelegt 4 Beilagen.

Rozszyfrowane teksty, maszynopisy.

Haus, - Hof und Staatsarchiv, Krieg, PA I, karton 1025, plik $\beta$, folio 91.

Załącznik nr 1. Telegram szefa austro-węgierskiego Sztabu Generalnego nr 131537 do Ministerstwa Obrony Krajowej w Wiedniu.

Laut Zuschrift des Generalgouverneur Warschau haben 155 österreichisch-ungarische Staatsangehörige der polnischen Legionen urn Übersetzung zum k.u.k. Heere gebeten. Diese Anträge wurden vom Oberbefehlshaber genehmigt. Das Legionkommando ist von Generalgouverneur Warschau beauftragt, diese Personen derart zu instradieren, dass sie am 10 August in Piotrków eintreffen, wo sie sich beim Kreiskornmando zu melden haben. Abschrift dieser Verfügung nebst Vorzeichnissen wurde dem genannten Kreiskommando zugestellt. Das Armee Oberkommando ersucht, das Kreiskommando Piotrków wegen wieterer Behandlung dieser Personen direkt anzuweisen und die sonstigen Verfügungen zu treffen. Nach [herstellten] Ansicht wären dieselben im Sinne der dortigen Erlasse [Präs. -- ?] Nr 9859 durch römische 2 und 11459 durch römische 2 vom 8 beziehungsweise 22 Mai 1917 $\mathrm{zu}$ behandeln. Das Legionen Kommando wird durch Oberst von Paić beauftragt, eine Liste dieser Personen gemäss dortigen Erlass [Präs.] Nr 11459 durch römische 2 dem Minister für Landes Verteidigung und direkt Landes Ergenzungs Bezirk Krakau vorzulegen.

\section{Załącznik nr 2}

Vertreter des k.u.k. Armeeoberkommandos beim kaiserlich deutschen Generalgouvernement Warschau Betrifft k.u.k. Untertanen in der Polnischen Legionen 


\section{An}

das k.u.k. Armeeoberkommando, Quartiermeisterabteilung in Warschau Den 3 Juli 1917.

Im meinem Berichte Nr 4465 betreffend die „Vereinbarungen iiber die polnische Armee" habe ich gemeldet, dass deutscherseits der Verbleib der Bestimmung iiber das „Recht der österreichisch - ungarischen Staatsangehörigen aus der polnische Armee auszuscheiden", in der bisherigen Form abgelehnt wurde und dass eine Verlautbarung geplant war, die hiefür einen Ersatz schaffen sollte.

Diese Verlautbarung ist bereits in folgender Form geschehen: "Es ist allen Angehörigen der Polnischen Wehrmacht mitzuteilen, dass k.u.k. Untertanen, welche die Rückkehr in den k.u.k. Heeresverband wünschen, dieses zu melden haben. Gesuche, welche später als vier Wochen nach Bekanntgabe dieser Ansage vorgebracht werden, finden keine Berïcksichtigung.

Der Oberbefehlshaber

gez. von Beseler

General der Infanterie"

Die Bestimmungen des 2 Absatzes entspricht der von mir schon gemeldeten Anschauung der Deutschen, dass es unzulässig wäre, wenn für einem ganzen Teil der polnischen Armeees für alle Zukunft von dem guten Willen und Laune des einzelnen Soldaten abhängig gemacht würde, ob er in irgend einem beliebigen Momente noch weiter in dieser Armee bleiben will oder nicht.

Gegen diese Auffassung, die militärisch zweifellos gesund ist, wäre unserseits umsoweniger Stellung zu nehmen, als diese Bestimmung in den polnischen Kreisen den allerbesten Eindruck machte. Man leitet hierauf $\mathrm{ab}$, dass alle nicht binnen vier Wochen freiwillig aus der polnischen Armee ausscheidenden österreichisch-ungarischen Staatsangehörigen nunmehr ohne Zeitgrenze dem polnischen Heere erhalten bleiben.

Paić Oberst

\section{Załącznik nr 3}

K.u.k. Armeeoberkommando

Nr $131537 / 2$

Übertritt von 155 Legionären österreichisch-ungarischen Staatsangehörigkeit in k.u.k. Armee 
An

das k.u.k. Ministerium den Äussern in Wien

Standort des AOK am 4 August 1917.

In der Anlage wird die Abschrift einer Meldung des Oberst von Paić zur gefälligen Kenntnisnshme übermittelt.

Da es aus disziplinären Grïnden nicht angängig erscheint den Zeitpunkt des eventuellen Austrittes aus der polnische Armee dem Ermessen des Einzelnen zu iiberlassen, stimmt das AOK dieser Verfügung des Generalgouvernuers von Warschau zu.

Auf Grund dieser Verfïgung haben sich nunmehr 155 österreicsch-ungarische Staatsangehörige der polnischen Legionen zum Übertritte in die k.u.k. Armee gemeldet.

Das AOK hat hierauf an das k.k. Ministerium für Landesverteidigung das in Abschrift beiliegende Telegramm gerichtet und Oberst von Paić entsprechend angewiesen. Je eine Abschrift der zittirten Erlässe den k.k. Ministerium für Landesverteidigung, Krieg Ministerium 5 Abteilung, k.u.k. Chef des Ersatzwesens, k.u.k. Ministerium des Äussern durch Vertreter.

Arz General der Infanterie

\section{Załącznik nr 4}

\section{Telegramm vom 22 Mai 1917}

Angehörige des polnischen Hilfkorps, die österreichische oder ungarische Staatsbürger sind und über ihre Bitte aus dem polnischen Hilfskorps entlassen werden, ausnahmlos unbewaffnet zum Landwehr Ergänzungs Bezirk Kommando in Krakau absenden.

Land Ergänzungs Bezirk Kommando Krakau hat Wehrpflichtverhältnis dieser Personen festzustellen, dann dieselben auf Grund dieses Verhältnisses so zu behandeln, wie dies mit hiesigen Erlass Präs Nr 9859 römische 2 vom 8 Mai leitendes Jahres für in Heilanstalten befindliche Angehörigen des polnischen Hilfskorps österreichische oder ungarische Staatsangehörigkeit festgesetzt wurde, die in die polnische Wehrmacht nicht übernommen worden.

Kommando des polnischen Hilfskorps wäre durch Vertreter des AOK Obersten Paić zu veranlassen, alle derartigen bisher Entlassenen dem Ministerium für Landesverteidigung mittels Verzeichnissen direkt bekanntzugeben. In diesen Verzeichnissen wäre Legioncharge, Geburts- und Heimats- 
daten anzufïhren, dann ob und wohin diese Leute zur Erfüllung ihrer Wehrpflicht in der Macht der österreichisch-ungarische Monarchie abgesendet wurden.

Derartige Vezeichnisse wären bei Künftigen Entlassungen seitens des Kommandos den polnischen Hilfskorps dem Landwehr Ergänzungs Kommarido Krakau direkt einzusenden. Ergeht an das Kommando des polnischen Hilfskorps in Warschau und Vertreter des AOK beim kaiserlich deutschen Generalgouvernement in Warschau und zur Kenntnis an AOK Quartier Abteilung Militär Kommiando und Landwehr Ergänzungs Bezirk Kommando Krakau.

Ministerium für Landesverteidigung Präsidium 11459 römische 2.

\section{Dokument nr 25}

1917 sierpień 6, Berlin. - Telegram nr 528 ambasadora księcia Gottfrieda zu Hohenlohe do ministra Ottokara Czernina o rozmowie z kanclerzem Niemiec w sprawie przysztości Legionów Polskich.

Zu Euer Exzellenz Telegramm Nr 490.

Ich habe gestern auch lange mit dem Reichskanzler ïber die Angelegenheit der Verwendung der Legionen gesprochen und ihm sehr eindringlich nahegelegt, er solle sich doch nicht gleich zu Beginn seiner Amtstätigkeit von der Obersten Heeresleitung in politischen Fragen majorisieren lassen.

Herr Michaelis war sehr nachdenklich, versicherte mich aber, er werde in Kreuznach alles aufbieten, um die. Oberste Heeresleitung zu veranlassen, ihre diesbezüglichen Forderungen fallen zu lassen, nachdem es doch unbedingt verinieden werden müsse, dass der inneren Politik der verbiindeten Monarchie wegen Verwendung dieser 6000 Mann Schwierigkeiten erwächsen.

Ich glaube, es steigen Michaelis schon recht grosse Bedenken ïber seine künftige Stellung zur Obersten Heeresleitung auf, denn im Verlaufe unseres Gespräches betonnte er, es scheine ihm dringend erwïnscht, dass sollte der Welkrieg in sein letztes Stadium treten, Seine Majestät Kaiser Wilhelm nicht ständig im Hauptquartier bliebe. Er müsste hieher ïbersiedeln und das Grosse Hauptquartier sich irgendwo in der Nähe Berlins etablieren.

Ich werde den Kanzler in diesem seinen Vorsatz tunlich unterstiitzen, ob 
es ihm aber gelingen wird, in diesen Sinne zu wirken, erscheint mir bei der gegenwärtig im Hauptquartier herrschenden Stimmung noch sehr fraglich.

Tekst rozszyfrowanego telegramu, maszynopis.

Haus, - Hof und Staatsarchiv, Krieg, PA I, karton 1025, plik $\beta$ (eta), folio $79-80$.

\section{Dokument nr 26}

1917 sierpień 8, Wiedeń. - Depesza telefoniczna ministra Ottokara Czernina do Wilhelma Storcka z zamystami dotyczacymi przysztości Polskiego Korpusu Positkowego.

Euer Hochwohlgeboren wollen durch Generał von Cramon nachstehendes Telegramm raschestens an General Ludendorff gelangen lassen.

„Im vollen Einverständnisse mit dem Herrn Chef des Generalstabes und nach eingeholter Genehmigung Seiner k.u.k. Apostolischen Majestät erlaube ich mir, Euer Exzellenz nachstehend einen Vorschlag zu unterbreiten, welcher mir geeignet erscheint, die Frage der Verwendung des polnischen Hilfskorps an der Front in einer für alle Teile annehmbaren Weise zu lösen.

Der gegenwärtige Gegenstand des polnichen Hilfskorps beträgt 12153 Österreicher beziehungsweise Ungarn und 3541 Polen aus dem Königreiche, die den Fahneneid abgelegt haben. Von diesen wäre als Kader für die Armee ein Werbe - Ausbildungspersonal zuriickzubehalten, dessen Stärke nach den Aufstellungen des k.u.k. Generalstabes für das Werbepersonal 2475 Mann (1459 Österreicher, beziehungsweise Ungarn und 1016 Kongresspolen), für das Ausbildungspersonal 1044 Österreicher und circa 1300 Polen aus dem Königreiche beträgt. Es bliebe somit nach Abrechnung eines Krankenstandes von 1238 Mann ein Korps von 9637 Mann (darunter 8412 Österreicher) die für die Entsendung an die Front in Betracht kämen.

Da der Hauptgrund, weshalb die Polen des Königreiches sowie die galizischen eine Frontverwendung der Legionen perhorrsszieren ${ }^{1}$ der ist, dass so der Stamm des polnischen Heeres in kurzer Zeit aufgerieben wiirde, ist das k.u.k. Armeeoberkommando bereit. Eine Kompensation der Verluste an galizianern durch Einreihung galizischen Rekruten zu gestatten, während für die Verluste der kongresspolnischen Mannschaften der Kader und Werbung im Königreiche Polen Ersatz zu schaffen hätten. Um das weiteren den Gefühlen der Polen möglichst entgegenzukommen, wäre der an die Front 
abgebende Truppenkörper als geschlossene Einheit zum Schutze der Grenze des Königreiches zu verwenden und als dessen Kommandant der das Vertrauen der Legionen besonders geniessende Oberst Zieliński zu belassen.

Es wäre demnach das polnische Hilfskorps an Ober-Ost zu ïbergeben. Ich ersuche jedoch ausdrücklich um das Einverständnis, den Polen gegenïber erklären, dass diese Verwendung des polnischen Hilskorps eine "provisorische sei, die so lange anhält, als die militärische Lage dies erfordert".

Schliesslich würde ich den grössten Wert darauf legen, dass gleichzeitig mit der Entsendung der Legionen-an die Front die Durchfiihrung der Übergabe des Justiz - und Schulwesens an die polnische Behörden sowie die Einsetzung des Regentschaftsrates erfolgen könnte, wie ich dies dem Herrn Reichskanzler noch mündlich vorschlagen werde, damit die zu den Zentralmächten haltenden Elemente in Polen die Schwere Belastunsprobe der Entfernung des Gross des polnischen Hilfskorps aus Lande leichter, ohne an politischer Stellung zu verlieren, durchmachen könnten".

Czernin

Tekst przeznaczony do zaszyfrowanej depeszy, maszynopis.

Haus, - Hof und Staatsarchiv, Krieg, karton $\gamma$ (gamma), folio 120-124.

Do tekstu dołączone zestawienie liczbowe sił Polskiego Korpusu Posiłkowego.

1 W tekście zostało użyte obcojęzyczne określenie łacińskiego pochodzenia: „perhorreszieren", oznacza wstrząsać się lub wzbraniać się.

Stärke der polnischen Legion

Öster.-Ungarn Polen

\begin{tabular}{lrrr}
\hline a) Infanterie & 5300 & 823 & $=6123$ \\
Kavallerie & 715 & 180 & $=895$ \\
Artillerie & 1128 & 0 & $=1128$ \\
Technische Komp. & 100 & 0 & $=100$ \\
$\quad$ Sonstige Formatione & 1169 & 222 & $=1391$ \\
\hline & 8412 & 1225 & $=9637$ \\
$\quad$ & 1238 & & \\
$\quad$ Krankenstand & 1459 & 1016 & $=2475$ \\
$\quad$ Kadre & & \\
$\begin{array}{l}\text { b) Werbepersonal } \\
\text { c) Ausbildunspersonal } \\
\quad \text { für 1200 Rekruten Infanterie } \\
\text { für 328 Rekruten Artillerie } \\
\quad \text { für 50 Rekruten techn. Truppen }\end{array}$ & 1044 & ca 1300 & $=2344$ \\
& & & \\
\hline
\end{tabular}

$12153 \quad 35411269$. 


\section{Dokument nr 27}

1917 sierpien 9, Baden. - Depesza telefoniczna nr 22027 Wilhelma von Storcka do ministra Ottokara Czernina z przytoczonym tekstem odpowiedzi generała Ericha Ludendorffa w sprawie przysztych losów Polskiego Korpusu Positkowego.

Deutsche Militärmission beim Armeeoberkommando (Major Fleck) übermittelt mir soeben die Antwort General Ludendorffs auf das Telegramm Euer Exzellenz von gestern betreffend unseren Vorschlag für die Verwendung des.polnischen Hilfskorps. Diesel be ist wider Erwarten negativ und lautet.

„Euer Exzellenz Fernschreiben betreffend polnischen Hilfskorps habe ich erhalten. Ich hege Euer Exzellenz Vorschläge die grössten Bedenken und behalte mir vor, die Angelegenheit hier am 10 August mit Euer Exzellenz zu besprechen. Ich möchte aber schon jetzt meinen Standpunkt grundsätzlich in zweifacher Richtung festlegen:

1. Wir brauchen die Mannschaft sofort an der Front; eine Verzögerung darf nicht mehr eintreten.

2. Ich muss auf der Durchführung der Trennung der k.u.k. Staatsangehörigen und der gebürtigen Polen bestehen. Diese Massnahme ist zwischen Oberst Paić und General von Beseler vereinbart worden, hat die Zustimmung der in Betracht kommenden österreichisch-ungarischen Stellen gefunden und sollte bis 1 Juli durchheführt sein. Der eigentretene Aufschub ändert an dem Grundsätzen nichts. Meinem Standpunkte und den getroffenen Abmachungen wïrde wenigstens einigermassen Rechnung getragen werden, wenn eine k.u.k. Formation in der von Euer Exzellenz gegebenen Zahl von 9637 Man, bestehend nur aus österreichisch-ungarischen Unterstanen des polnischen Hilfskorps, den k.u.k. Armeeoberkommando zur Verwendung bei Ober Ost (Linsingen)) zur Verfügung gestellt würde".

Tekst rozszyfrowanej depeszy, maszynopis.

Haus, - Hof und Staatsarchiv, Krieg, PA I, karton 1025, plik 56 c Juli August, folio 125-126. 


\section{Dokument nr 28}

1917 sierpień 9, Baden. - Depesza telefoniczna nr 22061 Wilhelma von Storcka do ministra Ottokara Czernina o zgodzie szefa austro-węgierskiego Sztabu Generalnego na pozostawienie 1225 obywateli Królestwa Polskiego $w$ tej części sit Polskiego Korpusu Positkowego, która miata odjechać na obszar Galicji.

Zu meiner Telefondepesche Nr 22027.

Der Chef des Generalstabes ersucht mich, Hochdenselben mit Bezug auf das auch ihm bekanntgewordene Telegramm Generał Ludendorffs an Euer Exzellenz Nr 21 783/P. zu melden, dass er vom militärischen Standpunkte nichts dagegen einzuwenden hätte, dass die in dem an die Front abgebenden Teile des polnischen Hilfskorps befindlichen 1225 Polen aus dem Königreiche durch die gleiche Anzahl Österreichischer und Ungarn aus dem Werbepersonale (unter dem sich 1459 Österreicher beziehungsweise Ungarn) und aus dem Ausbildungspersonale (unter dem sich 1044 Österreicher beziehungsweise Ungarn befinden) ersetzt werden.

Das an die Front abgebende Hilfskorps wïrde sodann aus 9637 Mann, und zwar nur Österreichern und Ungarn bestehen.

Tekst rozszyfrowanej depeszy, maszynopis.

Haus, - Hof und Staatsarchiv, Krieg, PA I, karton 1025, plik 56 c Juli August, folio 127.

\section{Dokument nr 29}

1917 sierpień 9, Wiedeń. - Depesza telefoniczna austro-węgierskiego ministra spraw zagranicznych Ottokara Czernina do przedstawiciela austriackiej dyplomacji przy Naczelnej Komendzie Armii kawalera von Storcka z prośba o przekazanie szefowi Sztabu Generalnego informacji zwiazanej z odmownym stanowiskiem ministerstwa wobec propozycji niemieckiego generata Ericha Ludendorffa.

Mit Bezug auf die heute mir durch Euer Hochwohlgeboren ïbermittelte Depesche des Generals Ludendorff in der Legionenfrage wollen Sie dem Herrn Chef des Generalstabes in meinem Namen folgendes mitteilen:

„Die Weigerung der Deutscchen Obersten Heeresleitung, unseren auch 
nach der Ansicht Baron Arz in militärischer Hinsicht die deutschen Wünsche vollkommen befriedigenden Kompromissvorschlag anzunehmen, beweist neuerlich, dass für die Deutsche Oberste Heeresleitung die militärische Seite der Frage hinter der politischen zurücktritt.

Ich kann diesen Standpunkt nicht akzeptieren.

Ich würde Baron Arz bitten, auch seinerseits keinerlei Zusage im Sinne der Erfüllbarkeit des deutscher Postulates zu machen, sondern im Gegenteil an General Ludendorff $z u$ telegraphieren, dass auch er neue Proposition unannehmbar findet.

Tekst depeszy przeznaczonej do zaszyfrowania i wysyłki, maszynopis. Haus, Hof und Staatsarchiv, Krieg, PA I, karton 1025, plik 56 c Juli August, folio 128-129.

\section{Dokument nr 30}

1917 sierpień 1917, Wiedeń. - Telegram nr 2 wystany przez Müllera austro-węgierskiemu ministrowi spraw zagranicznych Ottokarowi Czerninowi o stanowisku przedstawicieli różnych polskich ugrupowań politycznych wobec zamystów dotyczacych wydzielenia z Legionów Polskich obywateli Austrii $i$ Wegier.

Von verlässlicher polnischer Seite wird mitgeteilt, dass die in immer weiteren polnischen Kreisen bakannt werdende Nachricht von der neuerlichen Absicht der Deutschen, die Entfernung unserer Staatsangehörigen aus den Legionen durchzusetzen, Konsternation hervorruft und dass die Rückwirkung einer etweigen solchen Massnahme auf die für die ersten Septembertage einberufene Vollversammlung der galizischen Reichsrats und Landtagabgeordneten eine verhängnisvolle sein wïrde.

Auch wird darauf hingewiesen, dass die Herausziehung der Mehrzahl der Legonäre als ein endgiltiger Verzicht der Zentralmächte, die Polen an sich zu fesseln' und ein polnisches Heer zu bilden, gedeutet werden wïrde, was nach polnischer getroffenen Übereinkommens durch einseitige Herausziehung unserer Statsangehörigen aus den Legionen wäre schon deshalb höchst bedenklich eine solche Vorgangsweise die weitgehendste Erregung in Polen sowohl wie in Galizien hervorrufen, hierlands wesentliche innerpolitische Schwierigkeiten schaffen und die Bildung von Organen des polnischen Staates, die ihre Mandate von den Zentralmächten entgegenzunehmen be- 
reit wären sehr erschweren, wenn nich unmöglich machen würde.

Da der von mir im Einvernehmen mit dem k.u.k. Armeeoberkommando gemachte Kompromissvorschlag, welcher nach Ansicht des letzteren eine vollkomen befriedigende Lösung der militärischen Seite der Frage dargestellt hätte, Euer Exzellenz unannehmbar erscheint, sehe ich nicht genötigt, auf den Standpunkt zurüzukehren, welchen ich dem Herrn Reichskanzler gegenïber bei dessen Auffasung umso bedauerlicher wäre, als die Eidesverweigerung nur eine vorübergehende Episode sei, welche nach Einsetzung des Regentschaftsrates ihrern Abschluss finden dürfte. Der Verzicht auf die Heeresbildung wïrde aber als unmittelbare Folge eine Änderung der Haltung der polnischen Partei in Russland (Lednicki ${ }^{1}$ ) haben, die bisher erfolgreich das schon weit gediehene Projekt der Bildung einer polnischen Armee in Russland unter der Motivierung verhindert habe, dass es nicht angängig sei, während im Mutterlande die eigentliche polnische Armee in Bildung begriffen sei, im Auslande ein zwietes polnisches Heer aufzustellen, dessen Aufgabe sein könnte, die Armee des Königreiches Polen zu bekämpfen.

Botschafter Graf Tarnowski reist heute Marienbad, hofft Fürsten Lubomirski bezüglich der Legionenangelegenheit volständig zu beruhigen.

Mïiller $^{2}$

Tekst odszyfrowanego telegramu, maszynopis.

Haus, - Hof und Staatsarchiv, Krieg, PA I, karton 1025, plik 56 c Juli August, folio 137-139.

1 Chodzi o Aleksandra Lednickiego, prezesa Komisji Likwidacyjnej do Spraw Królestwa Polskiego.

2 Nie udało się ustalić kim był ów Müller.

\section{Dokument nr 31}

1917 sierpień 11, Kirn. - Telegram austro-węgierskiego ministra spraw zagranicznych Ottokara Czernina do cesarza Karola I z prośba o odtożenie decyzji dotyczqcej Legionów Polskich do tego czasu aż przedstawi swoje ustne propozycje.

Ich Ersuche Euer Exzellenz Seiner Majestät nachstehende Meldung zu erstatten und auch Baron Arz Kenntnis zu geben. 
In der Legionsfrage hat soeben eine Besprechung stattgefunden, bei welcher die deutsche Heeresleitung starrsinnig auf ihren ablehnenden Standpunkte im Sinne des letzten Telegramms General Ludendorffs verblieben ist. Dieser Standpunkt erscheint für uns inakzeptabel. Ich bitte Euer Majestät, einstweilen keine Entscheidung zu treffen und meinen mündlichen ergebensten Bericht erst anzuhören. Ich werde mir dann erlauben, Voschläge zu unterbreiten. Vorerst habe ich gar nichts zugestanden und die Deutsche Oberste Heereslaeitung ist bereit, bis nach dem 17 dieses Monats zu warten.

Tekst telegramu przygotowanego do zaszyfrowania i wysyłki, maszynopis. Haus, - Hof und Staatsarchiv, Krieg, PA I, karton 1025, plik 56 c Juli August, folio 140.

\section{Dokument nr 32}

1917 sierpień 13, Warszawa. - Pismo nr 141/P barona Lago do ministra Ottokara Czernina dotyczqce raportów składanych przez legionistów w sprawie przeniesienia do armii austro-węgierskiej

Kürzlich hat sich hier das sensationelle Gerïcht verbreitet, dass alle Legionäre österreichischer Staatsangehörigkeit um die Übersetzung in die k.u.k. Wehrmacht nachgesucht haben.

Nach den zuständiger Stelle eingeholten Informationen ist die Nachricht in dieser Form zwar nicht wahrheitsgemäss, es haben aber tatsächlich ungefahr 1000 Legionäre (des Infanterieregiments $\mathrm{Nr}$ 1, des Ulanenregiments $\mathrm{Nr} 1$ und Artillerie) an seine K. Und K. Apostlische Majestät gerichtete Gesuche dem Legionskommando vorgelegt, in denen sie um die Entlassung aus den polnischen Legionen bitten.

Diese in Erscheinung tretende Bewegung - welche den bisher polnischerseits so leidenschaftlich vertretenen Postulaten direkt entgegenläuft - ist auf eine heftige Agitation der Vertrauensleute Piłsudskis zurückzuführen, welche jetzt die Losung verbreiten, dass „kein Ehremann” in der polnische Wehrmacht unter den gegenwärtigen Bedingungen (Verhaftung Piłsudskis, deutscher Oberbefehl, Waffenbrüderschaft mit Deutschland et cetera) verbleiben dïrfe.

Wie mir der zum Generalstabschef der polnischen Legionen wieder ernannte Major von Zagórski mitteilte, beabsichtgt General von Beseler, als für Entlassunggen zustän diger Kommandant, den Gesuchen jener Antrag- 
steller Folge zu geben, von welchen es erwissen ist, dass sie Rädelsführer oder doch wenigstens überzeugte Anhänger dieser Bewegung sind, während man versuchen will, die übrigen Bittsteller, von welchen man annimmt, dass sie zur Einbringung der Gesuche verführt oder gezwungen worden sind, zur Zurückziehung der Petitionen zu veranlassen. (Die Gesuche sind nicht gremialiter abgefasst).

Die entlassenen Legionäre sollen den k.und k. Militärbehörden überstellt werden.

Major von Zagórski äusserte sich mir gegenüber im allgemeinen optimistisch über den zu gewärtigenden Verlauf der Ereignisse; er ist der Ansicht, dass es gelingen wird, die Legionen durch Ausscheidung der geistigen Urheber zu reinigen und die ïbrigen Legionäre (meist Mannschaftspersonen) zu einer Sinnesänderung zu bringen; vorläufig sollen keine Anzeichen für ein Übergreifen auf anderen - weniger unter der Faszination Piłsudskis stehenden - Legionstruppenteile vorhanden sein; Major von Zagórski hofft übrigens, ein solches durch scharfes Zupacken jetzt noch hintanzuhalten.

Die mir von anderen Legionsoffizieren erteilten Informationen lauten allerdings weniger zuversichtlich. Die Agitation soll derart in die Bevölkerung gedrungen und so heftig sein, dass eine bedeutende Charakterfestigkeit beim Einzelnen vorausgesetzt werden mïsse, um trotz aller Anfeindungen in den Legionen zu verbleiben; deartige persönliche Eigenschaften sind aber innerhalb der Legionen, welche aus ganz heterogenen Elementen zusammengewïfelt und in Warschau nicht bodenständig sind, wohl nicht in entsprechendem Masse anzutreffen, weshalb eher mit der Ausbreitung der Bewegung zu rechnen zei, trotzdem die Legionäre wohl wissen, dass sie nach ihrer Entlassung unverziiglich in die k. und k. Wehrmacht eigestellt und voraussichlich bald an die Front abgeben werden.

Die Absichten der Urheber dieser neuesten Agitationen sind leicht zu erkennen: es soll die Allmacht Piłsudskis klar demonstriert und zugleich die Bildung einer regulären polnischen Armee erschwert werden, in welch' letzterem Bestreben die Sozialisten bei den Nationaldemokraten die tatkräftigste Unterstützung finden. Es dürfte auch nicht ohne Absicht geschehen, dass das lancierte Gerïcht hervorhebt, die Legionäre hätten sich zum Übertritt in die k. und k, Armee gemeldet. Hiedurch soll eine Verstimmung zwischen uns und den Deutschen hervorgerufen und unser Wohlwollen captiert werden, während tatsächlich in erster Linie der Zerfall des entstehenden polnischen Heeres angestrebt ist. Es erscheint mir auch nicht ausgeschlossen, dass, falls die Zahl der entlassenen Legionäre eine bedeutendere werden solle, an uns polnischerseits die Forderung gestellt werden könnte, diese Mannschaften 
nicht zu ihren Ergänzungsbezirkskommandos einrückend zu machen, sondern sie in eigene Abteilungen zusammenzustellen, obwohl es den Einsichtigeren auch hier bakannt ist, dass derlei Experimente - ganz abgesehen von allen Bedenken - schon vom technischen Standpunkte aus wenig sympatisch erscheinen müssen.

Wie ich von Legionsoffizieren streng vertraulich erfahre, soll Abgeordneter Moraczewski einer der hauptsächtlichsten Anstifter der Bewegung sein.

Der k. und k. Legationsrat: Lago

Odpis rozszyf rowanego telegramu, maszynopis. Haus, - Hof und Staatsarchiv, Krieg, PA I, karton 1025, plik $\beta$, folio 92-95.

\section{Dokument nx 33}

1817 sierpień 15, Lublin. - Pismo nr 85 przedstawiciela austro-węgierskiego Ministerstwa Spraw Zagranicznych barona Ottona von Hoenninga do ministra Ottokara Czernina dotyczące raportów sktadanych przez legionistów o przeniesienie do armii austro-wegierskiej.

Ich habe soeben das Konzept des Berichtes Freihers von Lago's vom 13 dieses Monats Nr 141 - A erhalten und kann meinerseits nur bestätigen, dass eine ganze Reihe von Gesuchen seitens Legionären österreichischer Staatsangehörigkeit bei den Regimenten und dem Legionskommando einlaufen, von denen viele an Seine k.u.k. Apostlische Majestät gerichtet sind, manche dïrften auch mit Umgehung des Dienstweges abgesendet werden, in welchen um die Aufnahme in die k.u.k. Armee gebeten wird.

Auch davon habe ich Kenntnis, dass die meisten dieser Legionäre iiberzeugt sind, sie würden bei uns in besonderen Formationen vereint werden, so dass damit die Institution der polnischen Legionen in unserem Heere wiederaufleben wïrde.

Sehr warscheinlich ist, dass man damit Piłsudski Gelegenheit bieten will, nun auf unserer Seite Einfluss zu gewinnen.

Von sehr vertrauenswürdiger polnischer Seite wurde mir nahegelegt, doch dahin $z u$ wirken, dass etwa $z u$ uns iibertretende Legionsoffiziere ja nicht in rein polnische Regimenter, womöglich in deutsche oder tschechische, mindestens aber in solche mit ruthenisch-polnischen gemischten Bestand 
eingeteilt werden, um jedes Aufleben der Piłsudski - Psychose unmöglich zu machen.

Ich bin trotz des lange ïberschrittenen halben Jahrhunderts ein Optimist geblieben, wie man aber nach allen Erfahrungen heute noch damit rechnen kann, „die Legionen zu reinigen und sie zu einer Sinnesänderung zu bringen" (was nach Berichte Baron Lagos der Generalstabsschef Major Zagórski erhofft) ist mir denn doch ein Rätsel und da teils ich vollkommen Lago's Skeptizismus.

Ganz offen gestande ist es mir iibrhaupt unbegreiflich, wie man mit der Bildung der polnischen Armee durch deutsche Instruktoren unter deutschen Befehl noch ernstlich rechnen kann, da müsste man doch vorher $85 \%$ aller in den Legionen vorhandenen Elemente mit der Wurzel entfernen und mit der bäuerlichen Rekrutierung vorerst einen ganz Neuen Stamm schaffen, der dann als Kader diesen könnte. Bis das alles geschehen, stehen wir aber hoffentlich vor dem Ende des Krieges.

$\mathrm{Ob}$ eine polnische Regierung imstande sein wird, eine Armee aufzustellen, lasse ich dahingestellt. Die ganze hiesige Bevölkerung ist - wie auch Piłsudski sehr richtig erkannt hatte - dermassen amilitärisch, sie hat sich (leider auch von fremden Mustern unterstützt) dermassen angewöhnt, politisches [Kliquenwesen - ?] in jede Angelegenheit hineinzutragen, dass meine Zuversicht keine grosse ist.

Allerdings hat sich die polnische hohe und höhere Geselschaft seit jeher zwischen den lieben Gott und das Volk gestellt und betrachtet dieses als den noch „unerlösten” Teil, über den der Himmel nur mit Einveständnis der Gesellschaft verfïgt.

Dem Volke selbst eine Stimme einzuräumen fällt niemandem ein. Daher auch dieser Optimismus, diese heute schon ans Lächerliche grenzende Überzeugung: "Wir verfügen, der Bauer ist ans Gehorchen gewöhnt”.

Die russische Regierung hat den Grundbesitzer durch ihre Bauernpolitik im Schach gehalten, seit Einsetzung des polnischen Wirtschaftsrates und der Erntezentrale hört man die Dorfältesten schon heute sagen: "Wir geben viel lieber dem Kreiskommando als den Herren, die mit unserem Getreide Geschäfte machen werden".

Der polnische Bauer war hier allerdings ans gehorchen gewöhnt, aber der Obrigkeit, nicht dem Grundbesitzer und deshalb wäre auch für uns der hiesige Bauer, der intelligent und sein sehr guter Arbeiter ist, der wichigste Faktor, man darf ihn sich nur nicht wieder aus der Hand spielen lassen. 
Tekst rozszyf rowanego telegramu, maszynopis.

Haus, - Hof und Staatsarchiv, Krieg, PA I, karton 1025, plik $\beta$, folio 97-98.

\section{Dokument nr 34}

1917 sierpień 17, Wiedeń. - Anonimowe pismo o stanowisku polskich środowisk w sprawach dotyczacych rozwiqzania kwestii polskiej.

Der Warschauer Stadtpräsident Fürst Zdislaus Lubomirski heute wohl der einflussreichste und angesehenste Mann in Polen, sprach h.a. vor un gab bei diesem Anlasse der Überzeugung Asdruck, dass es ihm zusammen mit Erzbischof Kakowski künftigen im Regentschaftsrate gelingen dürfte, die Unterstützung der Mehrheit des Lande für eine Staatsaufbaupolitik zusammen mit den Zantralmächten zu finden. Sogar die Linken hätte ihm diesbezügliche Zusicherungen gegeben; nur auf die Nationaldemokraten, die ihren in den Ententeländern befindlichen Führer wegen pronzipiell ententophil sein, glaube er nicht rechnen zu können.

Vorbedingung freilich für das Gelingen seiner Pläne sei, dass nicht etwa vor der Bildung der polnischen Regierung die polnischen Legionen an die Front geschickt w ürden. In diesem Fälle wïrde weder er noch der Erzbischof in den Regentschaftsrat eintreten und der Boykott der neuen Institutionen durch das Polentum sei in diesem Falle so gut wie sicher. Erwehnswert ist, dass der Fürst, der den Plan der Herausziehung der Österreicher aus den Legionen als catastrophal bezeichnete, das Kompromiss, welches Baron Arz vorgeschlagen hatte (Entsendung des Gros ohne Teilung nach Staatsangehörigkeit an die Front, Zurïckbehaltung eines kleinen gemischten Kadres) nach der Einsetzung der Regentschaftrates für diskutabel erkläte. Die Sache hänge eben, ob, wenn einmal eine polnische Regierung eingesetzt sei werde, die jetzt den Eid verweigernden Legionäre noch immer auf ihrem Standpunkt beharren würden. Sollte dies wieder sein Erwarten der Fall sein, so wäre nach Lubomirskis Ansicht tatsächlich ein so grosser Kadre für die polnische Armee ïberflüsssig und die Entsendung des Gros der Legionen an die Front ganz gerechtfertigt. Nur müsse eben dieser Zeitpunkt (Einsetzung des Regenrschaftsrates) abgewartet werden.

Sehr vernünftig und ruhig sprach der Fürst ïber Piłsudski, dessen konspiratorisch-agitatorische Tätigkeit er zugab. Sein Anwesenheit in Polen bilde in sozialer Beziehung wie auch für die Interessen der Zentralmächte eine grosse Gefahr. Andererseits machten die Deutschen ihn dadurch, dass 
sie ihn in einer Festung oder in einen Konzentrationslager gefangen hielten, zu einem nationalem Märtyrer, dessen ohnehin grosse Popularität ins Ungemessene steigen werde. Am Zwckmässigsten schiene ihm, wenn Pilsudski enthaftet und in die Deutschland eine gewisse Bewegungsfreiheit zugestanden, dagegen die Rückkehr nach Polen ihm unbedingt untersagte wïrde.

Schliesslich bemerkte der Fürst noch dass die Kandidatur des Botschafters Grafen Tarnowski für die polnische Ministerpräsidentstelle immer mehr im Lande an Terrain gewinne. Bei den letzten Warschauer Besprechungen hätten auch die Vertreter der deutschen Regierung, Graf Hatzfeld und Ministerialdirektor Lewald, erklärt, dass die deutsche Regierung ihren ablehnenden Standpunkt gegenüber der Person des Grafen Tarnowski nicht mehr so ganz unbedingt festhalte. Falls der Regentschaftsrat auf Tarnowskis Designirung bestehe, werde man, so meinte Fürst Lubomirski, schlisslich deutscherseits den Widerstand gegen ihn aufgeben.

Der Fürst verfehlte nicht, im Laufe des Gespräches wiederholt und deutlich sich für eine austropolnische Lösung in irgend einer Anlehnung bedürfte Polen in Zukunft. Die von Deutschland gewïnschte Anlehnung an das Deutsche Reich sei deswegen unmöglich, weil im ganzen Land auch nicht eine Person diese Lösung wïnsche. Ein Anschluss an das heutige Russland bedeute permanente Unsicherheit in jeder Beziehung. Deswegen müsse Polen an Österreich angegliedert werden, dies sei seine Überzeugung; zur Erreichung dieses Zieles sei es uiberaus wichtig, dass in Polen die Überzeugung durchdringe, dass Österreich-Ungarn nicht nur Sympatien für das Polentumhabe, sondern auch die Kraft besitze, diese Deutschland gegenüber-durchzusetzen.

Koncept pisma, maszynopis.

Haus, - Hof und Staatsarchiv, Krieg, PA I, karton 1025, plik 56 c Juli August, folio 141-145.

\section{Dokument nr 35}

1917 sierpień 19, Warszawa. - Pismo nr 143/P barona Lago do ministra Ottokara Czernina dotyczace spraw zwiazanych z wydzieleniem $z$ Legionów Polskich obywateli Austro-Wegier.

Laut Mitteilung des Generalstabschef der polnischen Legionen sind bei Kommando bisher ungefähr 2500 Entlassungsgesuche von Legionären 
österreichischer Staatangehörigkeit eingelangt. Dieselben stammen fast durchgehend von den seinerzeit unter dem Kommando Piłsudskis gestandenen Truppen (Infanterieregimwnt $\mathrm{Nr} 1$ und 5, Ulanenregiment $\mathrm{Nr}$ 1); ausserdem beteiligt sich an der Bewegung der grösste Teil der Aetillerie (fünf Batterien) und ein kleiner Teil des Infanterieregimants $\mathrm{Nr} 4$.

In den Gesuchen wird die Bitte um Entlassung meist damit motiviert, dass das Verbleiben der Petenten in der Legionen im Hinblick auf die gegenwärtigen Verhältnisse und angesichts der Verhaftung Piłsudskis, der polnischen Sachen nützen könne. In vielen Gesuchen wird die Solidarität mit den in Szczypiorno internierten Kameraden zum Ausdruck gebracht.

Major von Zagórski bemerkte ferner, dass das Kommando der polnischen Wehrmacht jetzt die Absicht habe, dem überwiegenden Teil der Gesuche Folge zu geben. Ferner sollen auch alle jene Offiziere entlassen werden, die sich weigern, den in den meisten Armeen systemisierten, bei den Legionen scheinbar erst jetzt abverlangten, Revers zu unterschreiben, wonach der Betreffende erklärt, keiner geheimen Geselschaft anzugehören. Ein scharfes Vorgehen scheint in diesem Belange umso notwendiger geworden zu sein, als es sich erwiesen hat, dass eine grosse Zahl von Legionsoffizieren durch einen Piłsudski, beziehungsweise dem Chef der POW, geheim geleisteten Eid sich tatsächlich als gebunden betrachten und sich gegebenenfalls auch dementsprechend verhält.

Vorläufig wurde mit der Entlassung der Offiziere begonnen, und wurden ihrer bisher 50 ausgechieden. Erst wenn diese Entlassungen beendet sein werden, wird mit jenen der Mannschaften begonnen werden.

Major von Zagórski glaubt - soweit er die Sache heute iiberblicken kann - dass ungefähr 3000 Mann entlassen werden dürften.

Lago

Rozszyfrowany tekst, maszynopis.

Haus, - Hof und Staatsarchiv, Krieg, PA I, karton 1025, plik folio 104-106.

\section{Dokument nr 36}

1917 sierpień 20, Lublin. -- Pismo barona Ottona von Hoenninga do ministra Ottokara Czernina dotyczace spraw zwiqzanych $z$ wydzielaniem obywateli Austro-Wegier $z$ Legionów Polskich i o stanie liczebnym Legionów. 
Die bekannte Eidesleitungsaffaire bei den polnischen Legionen sowie das Vorgehen der deutschen Okupationsbehörden gegen die Mitglieder der POW, sind auch auf die polnische Legionäre österreichisch-ungarischer Staatsbïrgerschaft nicht ohne Wirkung geblieben. Ihre Solidarität mit den infolge Verweigerung der Eidesleistung internierten Legionären einerseits, die Propagandatätigkeit der POW anderseits haben unter den Legionären österreichisch - ungarischer Staatsangehörigkeit die Überzeugung geschaffen, dass unter den gegebenen Verhältnissen an die Bildung einer polnischen Armee nicht mehr zu denken ist. Deshalb hat unter ihnen die solidarische Entscheidung platzgegriffen, aus den Reihen der Legionen auszutreten und in die k.u.k. Armee einzutreten.

Nahstehende statistische Übersicht veranschaulicht das gegenständliche Bild

\begin{tabular}{|c|c|c|c|c|c|c|c|}
\hline $\begin{array}{l}\text { Infanterie- } \\
\text { Regimente }\end{array}$ & Offiz. & Mann & $\begin{array}{l}\text { Öster.- } \\
\text { Offiziere }\end{array}$ & $\begin{array}{l}\text { ngarn } \\
\text { Mann }\end{array}$ & $\begin{array}{l}\text { Hievon us } \\
\text { aus den Le }\end{array}$ & $\begin{array}{l}\text { tlassung } \\
\text { n gebeten }\end{array}$ & Anmerkung \\
\hline & & & & & Offiziere & Mann & \\
\hline 1 Reg. & 40 & 700 & 40 & 700 & 40 & 700 & Nebenstehende \\
\hline $2 \%$ & 80 & 1300 & 80 & 900 & - & - & Daten \\
\hline $3 \%$ & 80 & 1450 & 80 & 1000 & - & - & sind „ungefahr” \\
\hline $4 \%$ & 40 & 800 & 40 & 800 & 40 & 800 & genommen \\
\hline $5 "$ & 45 & 670 & 45 & 670 & 45 & 670 & \\
\hline $6 "$ & 50 & 750 & 50 & 750 & - & - & \\
\hline 1 Ulanen Reg. & 7 & 220 & 7 & 220 & 7 & 220 & \\
\hline $2 "$ & 30 & 750 & 30 & 550 & - & - & \\
\hline Artil. Reg. & 50 & 2000 & 50 & 2000 & 50 & 2000 & \\
\hline Zusarnmen & 422 & 8640 & 422 & 7590 & 182 & 4390 & \\
\hline
\end{tabular}

Es sind somit gegenwärtig bei den polnischen Legionen ungefahr 422 Offiziere und 7500 Mann österreichisch - ungarischer Staatsangehörigkeit, von denen 182 Offiziere und 4390 Mann um die Entlassung aus den Legionen und um die Einreihung in die k.u.k. Armee gebeten haben. Im Falle der Entlassung aller Gesuchsteller wïden bei den polnischen Legionen noch 240 Offiziere und 3200 Mann österreichisch-ungarischer Staatsangehörigkeit bleiben.

Hiezu kommen die polnische Legionäre ehemaliger russischer Staatsangehörigkeit, die der Eidespflicht nachgekommen sind und zwar 110 Offiziere und 1486 Mann. Der Gesamtstand der polnischen Legionen wïrde demnach aus 350 Offizieren und 4685 Mann bestehen, welche Reduktion die volkommene Auflösung der Legionen bedeutet. 
Es bliebe nämlichnur das 2 und 3 Infanterie Regiment und das 2 Ulanen Regiment die polnische Legionen bestehen, dagegen das 1, 4, 5 und 6 Infanterie Regimenten, das 1 Ulanen Regiment, das Artillerie Regiment und die Sapp. Kompanie der polnischen Legion, die durchwegs aus Legionären österreichisch-ungarischen Staatsangrhörigkeit bestehen, sich auflösen müssen.

Hier sei erwähnt, dass die in Rede stehende Gährung unter den Legionären österreichisch-ungarischen Staatsangehörigkeitdie lediglich in den Entlassungsgesuchen ihren Ausdruck gefunden hat, im Momente der Einsetzung einer polnischen Regierung, die im Stande wäre, die Heeresfrage fest in die Hand zu nehmen, vollkommen verschwinden wïrde. Mindestens $80 \%$ dieser Legionäre, die gegenwärtig aus den Reihen der Legionen auszutreten beabsichtigen würden sich der neu eingesetzten polnischen Regierung sofort loyal gegeniiberstellen.

Angesichts dieser Sachlage wäre es die Aufgabe der leitenden Faktoren und erster Linie des Kommandos der polnischen Legionen bis zur Bildung der polnischen Regierung eine abwartende Haltung zu wählen und wenigstens keine Ereignisse herbeizuführen, die von der illegalen Presse als Propagandamittel ausgewertet werden könnten.

Rozszyfrowane pismo, maszynopis.

Haus, - Hof und Staatsarchiv, Krieg, PA I, karton 1025, plik $\beta$, folio 107-109.

\section{Dokument nr 37}

1917 sierpień [okoto 20 VIII], [Warszawa]. - Notatki przedstawiciela austro-węgierskiego Ministerstwa Spraw Zagranicznych w Warszawie Stefana Andriana dla ministra Ottokara Czernina z argumentacja przeznaczonq do rozmów z szefem austro-węgierskiego Sztabu Generalnego Arthurem Arzem von Strassenbergiem.

Der morgige Besuch des Baron Arz dïrfte mit neuerlichen Drängen der Deutsche Oberste Heeresleitung auf sofortiges Herausnehmen unserer Staatangehörigen resp. (!; tak w tekście) auf ausschlissl. (!) Frontverwendung der österr (!) Legionäre zusammenhängen.

Geben wir nach, so schädigen wir unseren Kredit in Polen sehr, die Bildung der polnischen Regierung wird unmöglich, oder man bekommt nur die minderwertigsten Leute dazu, und in Galizien haben wir r ücksichtsloserer 
parlamentarischer Opposition zu rechnen. Machen wir den Deutschen gar keine Konzessionen, so entsteht-eine unangenehme, auf die Dauer vielleicht unhaltbare Situation für unsere Armee Oberkommando.

Formell ist daran festzuhalten, dass die Deutschen keinerlei Anspruch auf Herausnahme oder differenzielle Behandlung unserer Staatsangehörigen haben, weil die früheren diesbezïglichen Abmachungen annuliliert sind durch den von uns angenommenen deutschen Vorschlag, dass unsere Staatangehörigen erst dann herausgenommen werden, bis ebensoviel Polen aus dem Königreich ausgebildet sind. Dies ist allen Polen damals gesagt worden und Deutschland kann uns unmöglich die Demütigung zumuten, dass wir auf einen Wink der Deutsche Oberste Heeresleitung hin dieses als grossen Erfolg ausgegebene Abkommen preisgeben. Der.Mittelweg, den die Deutschen auch deshalb annehmen müssten, weil General von Beseler selbst dem Staatsrat gegenïber den Grundsatz aufgestellt hat, dass die polnische Armee den Polen gehört und er nur im Eivernehmen mit ihnen über sie verfügen will, wäre meine Ärachtens der folgende: Wir unterscheiden zwei Zeitpunkte a) den jetzigen, b) den nach Einsetzung der polnischen Regierungsbehörden.

Wir erklären uns bereit, wenn im Zeitpunkte b) trotz der Einsetzung der Regierung die Soldaten aus dem Königreich den Eid nicht schwören wollen, unsere Staatangehörigen herauszunehmen und somit vollinhaltlich das jetzige Petit der Deutschen zu erfüllen. Schwören nach Eisetzung der Regierung die Polen den Eid, so entfällt wie-auch deutscherseits zugegeben werden wird, jeder Grund, unsere Legionäre herausziehen, weil ja die Armee, wenn sie doch zustandekommt, wirklich entsprechendgrossen einen Kadre braucht.

Der Zeitpunkt b) kann durch rasche Einigung ïber die Vorschläge, betreffend den Regentschaftsrat sehr bald herbeigefiihrt werden. Es ist ganz unmöglich. Dass ein so kurzes Zuwarten die angeblichen militärischen Notwendigkeiten empfindlich schädige.

Was den jetzigen Zeitpunkt (a) anbelangt so wïrden wir auch jetzt zum Herausnehmen der Österreeicher, oder was auf dasselbe herauskommt, ihre Frontverwendung bei Hinterlandsbelassung aller Kongresspolen, bereit sein, aber aus begriflichen politischen Gründen nur dann, wenn die Polen, denen man das ausdrücklich Gegenteil versprochen hat, sich mit dieser Neuen Wendung einverstanden erklären. 
Voraussichtliche Rückwirkung der neuen Legionenlösung auf die Vehältnisse in Galizien und Polen

Wenn auch Punkt 1 des neuen Ludendorff-Arzschen Vorschlages (Unterstellung des polnischen Hilfskorps unter das österreichisch-ungarische Oberkommando) zunächst bei den Polen einen giinstigen Eindruck im Sinne der austro-polnischen Lösung machen dürfte, so wird die Ausführung der anderen von den Deutschen verlangten Punkte, die der Natur der Dinge nach nicht lange hinausgeschoben werden kann, voraussichtlich sehr böses Blut machen und unsere etweige politische Arbeit im Königreich wie auch in Galizien empfindlich stören. Was jetzt ein Vorteil für uns scheint, das österreichisch-ungarische Oberkommando, wird sich dann gegen uns kehren und das ganze Odium der von den Deutschen ausschliesslich aus politischen Grïnden gestellten Bedingungen wird auf uns fallen, weil unser Armee Oberkommando die bezüglichen Befehle erlassen wird.

1. Die Verwendung der Legionen muss bei der Armee des Erzherzogs Josef stattfinden. Die Tragweite dieser Massnahme ist erst dann verständlich, wenn man weiss, dass durch zwei Jahre, als die Legionen seinerzeit noch unter unserem Kommando standen, das einstimmige Postalat aller Polen war, dass die Legionen an der polnisch-galizischen Front verwendet werden möchten. Dies galt auch späterhin als unanfechtbarer Grundsatz. Ändern wir das jetzt, so werden das ganze Odium wir zu tragen haben.

2. Obligatorische Herausziehung der kongress-polnischen Legionäre und (tak w tekście - MW)

3. Verbot, Legionäre aus dem Königreich in die Legionen aufzunehmen. Auch diese Massnahmen kommen jetzt auf unser Konto und die Polen werden aus ihnen die Deduktion ziehen, 1) dass wir die Deutschen den Polen gegeniiber immer behauptet haben, die Trennung der Österreicher von den Kongress-Polen verlangen und, 2) dass wir uns allermilitärischen Rechte in Polen selbst zugunsten der deutschen entäussert haben.

Dasselbe gilt für Punkt 4: Wir müssen uns verpflichten, unsere Legionen nicht $\mathrm{zu}$ vergrössern.

$\mathrm{Da}$ alle diese von den Deutschen ausbedungenen und von Baron Arz angenommenen Bedingungen notwendigerweise in den nächsten Wochen öfentlich bekannt werden, besteht die grösste Gefahr, das sich die öffentliche Meinung des Polentums zu allen unseren politischen Massnahmen, die ungefähr in dieselbe Zeit fallen, weit ablehnender verhalten werde, als es sonst der Fall wäre.

Alees in allem stellt sich das ganze Projekt als eine politisch geschickte 
Berechnung der deutschen Obersten Heeresleitung dar, diejenigen den Polen odiosen Massnahmen, welche das Scheitern der deutschen Heeresprojekte in Polen herbeigeführt haben, auf uns zu ïberwältzen und so durchzusetzen, dass, wenn schon eine deutsch-polnische Lösung sich als unmöglich erweist, auch eine austro-polnische ein für allemal umöglich sei.

Oberst von Zeynek gibt diese Absicht und die voraussichtlichen für uns abträglichen Wirkungen zu, meint aber, dass, wenn wir die deutschen Bedingungen nicht annehmen, sie zu Repressivmassregeln militärischer Natur greifen würden. (Wegnahme deutscher Truppen von der Ostfront etc). Dies dürfte wohl nicht wörtlich zu nehmen sein. Meines Erachtens müssten wir, um einigermassen ohne grosse politische Verluste aus der Affaire herauszukommen, durchsetzen, dass die Legion statt beim Erzherzog Josef bei Böhm [Ermolli] verwendet werden kann.

Vorläufig hat mir Zeynek versprochen, vorzuschlagen, dass die Legion, wenn sie unserem Armee Oberkommando ïbergeben ist, nicht sofort nach Ungarn kommt, sondern zunächst "reorganiesiert" werden soll und zwar in Westgalizien. Damit wären allerdings nur wenige Wochen gewonnen.

S. Andrian

Notatki, maszynopis.

Haus, - Hof und Staatsarchiv, Krieg, PA I, karton 1025, plik 56 c Juli August, folio 152-158.

\section{Dokument nr 38}

1917 sierpień 21, Wiedeń. - Dyspozycje austro-węgierskiego ministra spraw zagranicznych Ottokara Czernina dla ambasadora księcia Gottfrieda zu Hohenlohe $w$ Berlinie dotyczqce spraw zwiazanych z przyszłościa Legionów Polskich.

Abschrift eines streng vertaulichen Erlasses an Gottfried Prinzen zu Hohenlohe in Berlin ddo Wien, 21 August 1917, Nr 4594.

Wie Euer Durchlaucht bekannt, ist die deutscche Obesrste Heeresleitung in der letzten Zeit mit besonderer Insistenz auf die Frontverwendung der polnischen Legionen beziehungsweise die Herausnahme der 
osterreichisch-ungarischen Staatsaangehörigen aus denselben zurückgekommen und besteht nunmehr auf sofortiger Durchfïhrung der von ihr verlangten Massregeln. Das aber die Durchfïhrung der Ludendorffschen Vorschläge eine grosse und nachhaltige Aufregung sowohl in Polen wie in Galizien hervorrufen würde, deren voraussichtliche Folge eine wesentliche Zunahme unserer innerpolitischen Schwierigkeiten wäre, erachte ich es als unerlässlich, dass die bevorstehende österreichisch-ungarisch-deutsche Abmachung in der Frage, die ja in wesentlichen die Wünsche der deutschen Obesten Heeresleitung erfuillen soll, doch ihrem Inhalte nach und vor allem in der Form, in der sie zur Kenntnis der polnischen Öffentlichkeit kommt, mit einiger Riicksicht auf die bekanntlich seit Bestehen der Legionen polnischerseits geäusserten Wiinsche in Bezug auf diesen sogenannten "Kern der künftigen polnichen Arme" abgefasst werde, Ferner wïrde ich es fïr zweckmässig erachten, das wenige Tage nach der Mitteilung der bevorstehenden Frontverwendung der Legionen, welche Mitteilung kurz vor Durchfïhrung der Massregel zu erfolgen hätte, die Publizierung der auf Grund der letztèn Warschauer Beratungen zustande gekommeri Enunziationen der Zentralmächte (Allerhöchstes Handschreiben, Grundstatut und Regierungserklärung), auf die ich später zurïickkommen werde, vorgenommen werde.

Als wesentlichen Inhalt der an die Polen von uns zu richtenden Mitteilung in der Legionenfrage, welche eben die Hauptpunkte unserer neuen Verreinbarung iiber die Verwendung der Legionen, deren Einzelheiten zunächst im Einvernehmen der beiden obersten Heeresleitungen zu vereinbaren wären, zu beinhalten hätte, schwebt mir ungefähr folgendes vor.

Der Ernst des gegenwärtigen Augenblickes, in dem an drei Fronten die Offensive des Feindes gegen die Heere der Zentralmächte eingesetzt hat, erfordert die Anspannung aller Kräfte zum erfolgreichen Widerstande. So wird es den auch notwendig, das ungestellte polnische Hilfskorps, das nach wie vor bestimmt ist, der Kader des kïnftigen polnischen Heeres zu werden, für die Dauer der schweren Kämpfe an der Front zu verwenden. Wir hegen die Überzeugung, dass die Taten der Legionäre nich hinter denen der jahre 1915 und 1916 zurückbleiben werden, wo sie wiederholt in entscheidender Weise zum Ausgange glïcklicher Operationen beigetragen haben. Die Legion wird unter dem sie schon bei den eben genannten Kampfen so Hervorrragendes geleistet hat. ( $\mathrm{Zu}$ Euer Durchlaucht Information bemerke ich, dass der Vorschlag, die Legion während ihrer Frontverwendung dem österreichisch- ungarischen Oberkommando zu unterstellen, von der deutschen Obersten Heeresleitung selbst auisgegangen ist). Fïr die Zeit, wo die Legion sich nicht im Königreiche Polen befindet, wird das Ausbilduns- und 
Werbungpersonal, welches im Königreiche zurückbleibt (hier wäre anzudeuten, dass auch bei den im Königreiche verbleibenden Legionären nicht die gefürchtete Zweiteilung nach der Staatsbürgerschaft eintritt), für den Fortgang der militärischen Arbeit im Königreiche sorgen. Sobald es die militärische Situation möglich macht, kommt die Legion in das Königreich Polen zurück, wo es dann heffentlich gelingen wird, nach Beseitigung der noch im Wege stehenden Hindernisse die Heeresbildung erfolgreich durchzufuihren.

Am Schlusse der Mitteilung wäre Bezug auf die unmittelbar bevorstehenden Enunziationen der Zentralmächte zu nehmen, durch die dem neuen polnischen Staate gesetzgebende und ausfürende Staatsorgane, an deren Spitze ein Regentschaftsrat und ein polniches Ministerium steht, verliehen werden, was nichts weniger zu bedeuten habe, als die effektive Errichtung des polnisches Staates.

Was nun diese Regierungsenunziationen selbst anbelangt, so habe ich, wie Euer Durchlaucht meinen heutigen Erlasse Nr 4595 entnehmen werden, an den Elaboraten der Warschauer gemischten Kommission gewisse Änderungen vorgenommen, welche das Wesen des zwischen den deutschen und österreichisch-ungarischen Vertretern Vereinbaren jedoch nicht tangieren.

Euer Durchlaucht wollen der kaiserlich deutschen Regierung gleichzeitig meinen obenstehenden Vorschlag, betreffend die Lösung der Legionenfrage beziehunsweise die Bekanntgabe dieser Lösung, wie auch die Elaborate, betreffend den Regentschaftsrat und das Grundstatut für Polen, mitteilen und um deren Zustimmung zu meien Vorschlägen ersuchen. Hiebei wollen Euer Durchlaucht nachdrücklich der Ansicht Ausdruck verleihen, dass es entschieden opportun wäre, die Frontverwendung der Legionen, die unleugbar, trotz allem, gerade von den uns gut gesinnten polnischen Elementen als schwerer Schlag empfunden werden wird, dadurch auszugleichen, dass wir fast unmittelbar darauf die tatsächlich sehr bedeutenden Konzessionen bekanntgeben, welche den Polen in Bezug auf ihren Staatsaufbau gemacht werden sollen des Entwurfes Abmachung mit der Resume einer deutsche Regierung ud deutsche Oberste Heereleitung in der Legionen- und Staatsaufbaufrage.

Punkt 1). Den Polen wird gleichzeitig die Frontverwendug der Legionen und der unmittelbar bevorstehende Ausbau des polnischen Staates bekanntzugeben.

Punkt 2). Bezüglich der Frontverwendung wird vereinbart und den Polen in einer Interesse an der polnischen Heeresbildung bekundenden und die Leistungen der Legionen im Kriege hervorhebenden Weise bekanntgegeben: 
a) die gesamte ungeteilte Legion kommt, da die allseitigen Offensiven die Zusammenfassung aller Kräfte erheischt provisorisch solange es die Kriegslage erheischt an die Front. Sobald es die militärische Lage gestattet wird sie nach Polen zurückverlegt, um als Kadre für eine grössere polnische Armee zu dienen;

b) Vorschlag verbleibt das notwendige Ausbildung- und Werbepersonal, letzteres zur Hälfte aus Kongresspolen, zur Hälfte aus Österreichern bestehend im Königreich;

c) während der Frontverwendung wird die Legion unter österreichisch-ungarischen Oberkommando stehen.

Punkt 3). In der Enunziation über die Fronverwendung wird am Schlusse auch die umittelbar bevorstehenenden Monarchenkundgebung über den Ausbau des polnischen Staates verwiesen.

$\mathrm{Zu}$ dieser Behufe wird.

Punkt 4). Ehestens in kurzen Wege zwischen beiden Regierungen auf Grund der Vereinbarungen der österreichisch- ungarischen Kommission, die kürzlich in Warschau tagte nach vorausehender formaler Abänderung der nicht besonders glïcklich redigierten Entwürfe zwischen beiden Regierungen der definitive Text der drei zu publizierenden Staatsakte (Kaiserliches Schreiben an die Generalgouverneure, Grundstatut der Verfassung, Regierungserklärung) vereinbart.

Odpis dyspozycji, maszynopis.

Haus, - Hof und Staatsarchiv, Krieg, PA I, karton 1025, plik 56 c Juli August, folio 145-151.

\section{Dokument nr 39}

1917 sierpień 22, Warszawa. - Telegram barona von Lago do ministra Ottokara Czernina o zamiarze ratowania spraw polskiego wojska przez niektórych czotowych dziataczy orientacji proaustriackiej.

Das entschlossene Vorgehen des Legions - Kommandos bei Behandlung der Entlassungs gesuche (mein Bericht vom 19 dieses Monats $\mathrm{Nr}$ 143) hat offenbar sehr heilsam gewirkt; man fängt an einzusehen, dass durch sinnlose Agitationen ernste Gefahr für die Bildungsmöglichkeiten eines polnischen Heeres und Ausgestalltung des polnischen Staatswesens mutwillig heraufbeschweren wurde. Selbst Teile der Linken sollen eingelenkt haben. 
Fïrst Zdzislaw Lubomirski ${ }^{1}$ hat heute einigen Staatsratamitglieder und Hofrat Rosner Mitgeteilt, dass er-um polnisches Heer zu retten und durch seinen Einfluss weitere Abbröckelung hintanzuhalten - bereit wäre. Stellung des Kronmarschalls zu ïbernehmen (Herr von Niemojowski² scheint definitiv abgetan), wenn er mit Legionskommando Einvernehmen iiber Vorgehen bei Entlassungen erziele und von Deutschen Zusicherung erhalte, dass beziiglich der in Szczypiorno internierten Legionäre etwas geschieht, um öffentliche Meinung zu beruhigen.

Odszyfrowany telegram, maszynopis.

Haus, - Hof und Staatsarchiv, Krieg, PA I, karton 1025, plik $\beta$, folio 110.

1 Zdzisław książę Lubomirski, prezydent miasta Warszawy i późniejszy członek Rady Regencyjnej.

2 Ignacy Rosner. Niemojowski Wacław, marszałek Tymczasowej Rady Stanu.

\section{Dokument nr 40}

1917 sierpień 24, Warszawa. - Telegram nr 521 barona von Lago do ministra Ottokara Czernina o odmowie księcia Zdzistawa Lubomirskiego dotyczqcej objęcia stanowiska marszatka koronnego Tymczasowej Rady Stanu.

$\mathrm{Zu}$ meinem Telegramm nr 515 vom 22 dieses Monats.

Fürst Zdzislas Lubomirski sagt mir, dass er, nachdem er sich iiber hiesige Lage grïndlich informiert, die Stelle des Kronmarschalls nicht iibernehmen werde, weil er keine Hoffnung haben kann, in der Legionsfrage jetzt noch eine Besserung herbeizuführen, da die Agitation und die Verbitterung zu grossen Umfang angenommen haben. Durch Übernahme der Wiirde Kronmarschalls wïrde er Situation nur verwirren, sich politisch verbrauchen und die nachmalige Bildung einer polnischen Regierung hiedurch erschweren.

Seiner Ansicht nach ist das einige Mittel, um auch in der Legionensache wieder Ordnung zu schaffen, die ehebaldigste Berufung einer ponischen Regierung.

Odszyfrowany telegram, maszynopis.

Haus, - Hof und Staatsarchiv, Krieg, PA I, karton 1025, plik $\beta$, folio 112. 


\section{Dokument nr 41}

1917 sierpień 24, Warszawa. - Pismo nr 140/P barona von Lago do ministra Ottokara Czernina o wewnętrznej sytuacji w Legionach Polskich.

Innerhalb der polnischen Legionen herrscht jetzt nicht nur eine heillose Verwirrung, sondern es treten auch Fakten zu Tage, die schon Meuterei und Aufruhr beinhalten.

Ganz genaue Informationen sind einstweilen nicht erhältlich, einerseits, weil die hiesigen militärischen Stellen in vielen Fällen vorläufig auf die mehr oder weniger verlässlichen Meldungen einzelner Legionsoffiziere angewiesen zu sein scheinen, anderseits, weil sie infolge der bekannten militärischen Suszeptibilität von vornherein nicht geneigt sind, erschöpfende Auskünfte zu erteilen.

Auf Grund der Informationen der Vertretung des k.u.k. AOK und anderer verlässlicher Mitteilungen kann als feststehend vorläufig Nachstehendes berichtet werde.

Verschiedene Abteilungen haben dem Legionskommando schriftlich "den Gehorsam gekündigt". Gleichzeitig erstatten sie hievon die Meldung direkt an das k.u.k., in dem sie um Entlassung aus den Legionen bitten.

Anderseits aber verweigern in verschiedenen Fällen die Legionäre, die vom Legionskommando entlassen wurden, sich abtransportieren zu lassen und verlangeen, dass nicht einzelne Legionäre, sondern alle, die um Entlassung eingereicht haben, gleizeitig und gemeinsam - also die Manschaft mit ihren Offizieren - nach der Monarchie abtransportiert werden. Der Grund dieses Verhaltens scheint darin zu liegen, dass man neuerer Zeit den Legionären eingeredet hat, es wïrden auf Befehl Seiner K. und K. Apostolischen Majestät aus den entlassenen Legionären in Österreich neue Legionen augestellt werden.

Die vom Legionskommando zur Übernahme des Kommandos an Stelle der entalassenen Offiziere entsendeten werden in die Kasernen, beziehungsweise zum Dienste, oft gar nicht zugelassen.

In Dęblin haben die dortigen Abteilungen direkt gemeutert, indem sie dem zur Kommandoïbernahme entsendeten Legionsmajor von Rylski den Gehorsam verweigerten und seinen Befehlen gewaltsam sich wiedersetzten; auf Rylski wurde ein (misslungenos) Attentat mittelst einer Höllenmaschine versucht.- Diese Abteilungen sollen entwaffnet werden.

In verschiedenen Abteilungen haben sich "Soldaten Räte" nach dem Muster der russischen gebildet. 
Beim 1 Ulanenregiment haben die Mannschaften Pferde, ärarische Ausrïstungs-gegenstände, sowie auch teilweise Waffen und Munition verkauft (letztere wahrscheinlich an POW - Mitglieder).

Das Kommando der polnischen Wehrmacht scheint die Bereingung dieser Zustände ganz dem Kommando der polnischen Legionen ïberlassen zu wollen. Da dieses aber infolge der Unzuverlässlichkeit der eigenen Truppen keine Mittel hat, um seinen Befehlen den entsprechenden Nachdruck zu verleihen (da es doch vermieden werden muss, deutsche Truppen als Assistenz zu verwenden), so nehmen die Ereignisse in vielen Fällen einen vom soldatischen Standpunkt höchst unerquicklichen Verlauf.

Man dürfte in der Annahme nicht fehlgehen, dass General von Beseler nach seiner in wenigen Tagen zu gewärtigenden Rückkehr sich zu energischen Massnahmen veranlasst sehen dïrfte.

Anderseits wirft sich mir Frage auf, ob es nicht opportun wäre, unserserseits die Gerïchte ïber die angebliche Errichtung polnischer Legionen in der Monarchie in einer Euer Exzellenz entsprechend erscheinenden Weise energisch zu demonstrieren, wodurch auch der Zweck erreicht werden wïrde, eine grosse Anzahl irregeführter Legionäre vor einer Enttäuschung $\mathrm{zu}$ bewahren und allen eventuellen späteren polnischen Rekriminationen ïber eine angebliche Unaufrichtigkeit unseres Verhaltens vorzubeugen.

Wie ich aus Legionskreisen höre, soll der Legionsoffizier, Reichsratsabgeordnete Lieberman einer von jenen sein, die hier am meisten die Nachricht ïber die Bildung polnischer Legion in Österreich propagieren, ebenso Reichratsabgeordnete Moraczewski (durch Mittelpersonen).

In ähnlichen Sinne sollen auch verschiedene entlassene Legionsoffiziere, die noch nicht ins k.u.k. Heer in Krakau eingestellt wurden Propaganda entwickeln. So Legionsoberst Roja in Krakau, Legionsoffizier Norwid in Lublin und Legionsoffizier Kasprzycki in Radom. Eine Verantwortung bezüglich der Richtigkeit der letzteren Meldung kann ich nicht iibernehmen.

Der k.und k. Legationsrat Lago

Odszyfrowane pismo, maszynopis.

Haus, - Hof und Staatsarchiv, Krieg, PA I, karton 1025, plik $\beta$, folio 113-117. 


\section{Dokument nr 42}

1917 sierpień 24, Berlin. - Depesza księcia Gottfrieda Hohenlohe do ministra Ottokara Czernina o zwtoce w sprawach dotyczacych Legionów Polskich i kwestii polskiej.

Baron Andrian ersucht mich, Euer Exzellenz nachstehendes zu melden: „Habe soeben mit Staatssekretär Lösung Legionsfrege auf der von Euer Exzellenz angegebenen Basis besprochen. Er erklärtc zunächst, zur Frage des Junktims der Frontverwendung der Legionen mit der Publikation der Staatsakte bezüglich des Regentschaftsrates noch keine Stellung nehmen zu können, weil der Reichskanzler iiber die Opportunität einer baldigen Vornahme des polnischen Staatsaufbaues bisher nicht schliissig geworden. Er werde aber dem Reichskanzler, der heute abends ins Hauptquartier fährt, sofort unsere Propositionen mitteilen und ihn ersuche, der Obersten Heeresleitung klar zu machen, dass in irgendeiner Weise den politischen Bedenken Euer Exzellenz gegen eine die Polen allzu verstimmenden Lösung der Frage Rechnung getragen werden müsse.

Nach Riickehr des Herrn Reichskanzlers aus Kreuznach, die Samstag friih erfolgt, werde er mir Ergebnis der Besprechung unseres Vorschlages mitteilen.

In der Zwischenzeit sollen Referentenbesprechungen über unsere Abäderungen an den Warschauer Kommissionsbeschlüssen stattfinden"

Nach Rïcksprache mit Baron Andrian habe ich den Reichkanzler vor seiner Abreise noch aufgesucht und ihm in kurzen, aber sehr nachdrücklichen Worten klar gemacht, eine Lösung der Legionenfrage im Sinne, wie sie durch Baron Andrian hier vorgeschlagen wird, sei ohne ein deutschen Eingehen auf unsere Vorschläge beziiglich des Staatsaufbaues gänzlich ausgeschlossen.

Ich müsse ihn dringends ersuchen, sich im obigen Sinne zu entscheiden, da sonst die Lösung der Legionenfrage wieder auf unbestimmte Zeit hinausgeschoben erschiene.

Der Kanzler erklärte, er wïnsche nicht sehnlicher als diese Frage zu lösen und werde mir sofort nach seiner Rïckkehr aus Kreuznach eine Antwort im Gegenstande geben.

Tekst odszyfrowanej depeszy, maszynopis. Haus, - Hof und Staatsarchiv, Krieg, PA I, karton 1025, plik 56 c Juli August, folio 159 -160. 


\section{Dokument nr 43}

1917 sierpień 24, Berlin. - Depesza barona Stefana Andriana do posta Bogatscha o sprawach dotyczących Legionów Polskich i kwestii polskiej.

\section{Verehrter Freund!}

Die Ahnung, dass es sehr schwer sein werde, in der Legion- und Staatsaufbau- Frage hier zu verhandeln, wenn nicht vorher festgestelt wäre, in wie weit die massgebenden Leute disponibel sind, hat sich leider noch iiber meine Erwartung hinaus erfüllt. Kühlmann war die letzten Tage ganz unsichtbar; er un der Reichskanzler waren ganz absorbiert von den Verhandlungen des Reichstags-Hauptaussuschusses ïber die auswärtige Politik und nur durch grösste Insistenz gelang es mir, des Staatssekrtärs gestern abends habhaft zu werden, wobei ich ihm alle Argumente für die Kompromisformel des Herrn Ministers auseinnandersetzte, während gleichzeitig der Botschafter in einer kurzem Unterredung mit Reichskanzler seinerseits im selben Sinne sprach. Alls dies geschah im Eiltempo, weil eben der Reichskanzler noch gestern abends ins Hauptquartier muste und mir vor Allem daran lag, dass er möglichst informiert sei, bevor er Ludendorff spräche. Nun sind aber diese beiden massgebendsten Personen, Reichskanzler und Staatssekretär, noch ganz neu im Amt und in Folge dessen blutwenig ïber die polnische Frage informiert; umso schwieriger ist es unter solchen Umständen, sie in Kurzem von der Notwendigkeit zu iiberzeugen, unser Kompromiss anzunehmen. Was nun Hatzfeld, den polnischen Referenten, anbelangt, so ergab sich mit ihm eine erfreuliche. Meinungsïbereinstimmung in den Fragen, die wir besprachen, und er fand auch im Allgemeinen unsere Abänderung der Warchauer Kommissionsbeschlïsse eine wesentliche Verbesserung. Aber auch er sieht in diesen Tagen den Staatssekretär so güt, wie nicht. So fürchte ich, wird sich sein Eifluss zunächst nicht geltend machen können.

Bei Kühlmann war eines ganz ersichtlich: dass er vollkomme versteht, dass es die Pflicht des Auswärtigen Amtes sein muss, unserer Regierung möglichst galizisch-polnische Komplikationen zu ersparren und in Folge dessen der Obersten Heeresleitung zuzureden, unseren Wünschen entgegen zu kommen. Er hat dies auch ganz gewiss noch dem Reichkanzler, wie er mir versprach, vor dessen Abreise klar gemacht. Nun bleibt abzuwarten, wie Kreuznach sich zu dieser Einwirkung stellen wird. Ich bin besonders nach den letzten Vorschlägen, die sie gemacht haben, die ja eigentlich für sie keinerlei militärischen noch auch politischen Wert hatten, als den, uns 
voraussichtlich sehr bei den Polen zu diskreditieren, einigermassen skeptisch, ob Ludendorff ïberhaupt wünscht, uns Entgegenkomen in dieser Frage zu zeigen.

Eine andere recht grosse Schwierigkeit, unseren Kompromissvorschlag durchzusetzen, liegt meines Erachtens darin, dass die massgebenden deutschen Faktoren gar nicht mehr sicher zu sein scheinen, ob sie iiberhaupt den polnichen Staatsaufbau vornehmen und nicht etwa die ganzen Warschauer Kommissionsbeschlïsse in den Papierkorb werfen sollen. Kïhlmann hat mir dies angedeutet, „es wäre bisher noch keine Entscheidung gefallen, ob man nicht die ganze Staatsaufbau- Angelegenheit dilatorisch behandeln soll" und Hatzfeld hat noch hinzugefïgt, er glaube, die Rechte, die ohnehin schon durch die Ankïndigung des erweiterten Wahlrechtes verschnupft sei, und die man schonen müsse, würde eine tatsächliche Errichtung des polnischen Staates während des Krieges ungern sehen. Hiezu mag auch kommen, dass wenn die deutsche Regierung anfängt, an der Verwirklichung einer deutsch-polnischen Lösung zu zweifeln und die Politik der freien Hand mit Grenzrektifikationen und so weiter vorzuziehen, es ihr bequemer sein dürfte, das Tempo des polnischen Staataufbaues möglichst zu verlangsamen. Unter solchen Umständen dïrfte wohl kaum auf die Anregung eingegangen werden, die Staatsaufbau-Enunziationen möglichst zu beschleunigen und gleichzeitig mit der Frontverwendung der Legionen zu publizieren. Wohl verstanden, ich meine nicht, dass man sich hier schon zu einer solchen Politik im Gegensatze zum Manifest vom 5 November entschieden habe. Man ist vorläufig am Scheidewege, und vielleicht gibt unsere Anregung, den Staataufbau mit der Legionenfrage zu verkoppeln, den Anstoss, dass sich die massgebenden deutschen Kreise über diese wichtige prinzipielle Frage schlüssig werden. Nun wir werden vielleicht morgen oder iibermorgen in dieser Beziehung schon klarer sehen. Ich wollte hier nur andeuten, warum die Annahme unserer letzten Formel nicht etwa nur von der Einigung in gewissen redaktionellen Fragen und der Bereitwilligkeit, uns und den Polen die Pille zu versüssen, abhängt, sondern von einer sehr folgenschweren Entscheidung prinzipieller natur.

Ich wäre sehr dankbar, wenn Du die Güt haben wolltest den wesentlichen Inhalt meiner Zeilen dem Herrn Minister bekannt zu geben und dabei zu erwähnen, dass auch die Einigung über die Boxtierung unserer Enunziation an die Polen, für den Fall als diese überhaupt herauskommt - dadurch wesentlich erschwert ist, dass zwar Hatzfeld, wie gesagt, unseren Verbesserungen sympatisch gegenüber steht, der kompetente Referent des Reichamts des Innern über auf Urlaub ist. Er soll ïbrigens morgen zurïckkommen und dann möchte ich noch gerne eine Unterredung mit ihm haben. 
Im Übrigen nehme ich mir vor, morgen oder spätestens ïbermorgen, vorausgesetzt Eure Einwilligung, abzureisen, es sei denn, dass der Reichskanzler aus Kreuznach weder eine glatte Ablehnung, noch auch die Annahme unseres Vorschlages mitbringt, sondern irgendeinem neuen Kompromissvorschlag, der Aussicht auf rasche Einigung bietet. Im Zweifel ob ich bleiben soll, wïrde ich telegraphisch anfragen.

Die vollständige Einigung bezïglich der Enunziationen an die Polen wenn diese iiberhaupt noch, angesichts der hiesiegen Stimmung, Aktualität haben - abzuwarten, wïrde wohl weder ratsam noch praktisch sein.

Ich verbleibe, hochverehrter Freund S. Andrian

Tekst odszyfrowanej depeszy, maszynopis.

Haus, - Hof und Staatsarchiv, Krieg, PA I, karton 1025, plik 56 c Juli August, folio 163-165.

\section{Dokument nr 44}

1917 sierpień 24, Warszawa. - Depesza barona Lago do austro-węgierskiego Ministerstwa Spraw Zagranicznych o majacym nastapić wydzieleniu obywateli Austro-Węgier z Legionów Polskich.

Fïrst Zdislas Lubomirski sagt mir soeben, er habe von vertrauenswïrdiger Seite die bestimmte Mitteilung erhalten, dass alle österreichischen Staatsangehörigen in den Legionen (also auch jene, welche um ihre Entlassung nicht gebeten haben) iiber Verlangen Deutschlands vom k.u.k. Armeeoberkommando sofort einberufen und in das k.u.k. Heer eingestellt werden sollen. Diesbeziigliche Befehle seien schon erteilt.

Fürst Lübomirski fügte hinzu, dass ein solches Vorgehen den Zusammenbruch jeder Hoffnung auf Bildung eines polnischen Staatswesens bedeutet wiirde.

Ich antwortete ihm, dass Nachricht in dieser Form mir unwahrscheinlich erscheine, dass ich ihm aber demnächst authentische Informationen erteilen werde. Ich bitte Euer Exzellenz, mich in Lage hiezu zu versetzen.

Tekst odszyfrowanej depeszy nr 520, maszynopis.

Haus, - Hof und Staatsarchiv, Krieg, PA I, karton 1025, plik 56 c Juli August, folio 166. 


\section{Dokument nr 45}

1917 sierpień 25, Warszawa. - Depesza nr 522 barona Lago do austro-węgierskiego Ministerstwa Spraw Zagranicznych $z$ informacja o majacym nastapić odestaniu Legionów Polskich na Front.

Dem Legionskommando wurde gestern vom Generastabschef des Generalgouverneurs die zwischen deutschen Obersten Heereleitung und k.und k. Armeeoberkommando bezuglich Abgang der Legionen an die Front getroffene Abmachung mittgeteilt und Marschbefehl fïr morgen in Aussicht gestellt. Legionskommando erhob gestern bei Kommando der Polnischen Wehrmacht Vorstellung gegen Verwendung der Legionen ohne Einvernehmen mit Staatsrat und betonnte, dass Legionen nur als Division des polnischen Heeres verwendet werden können.

Staatsrat ist in Kentnis der Vorgänge. Nach Äusserung des Vizekronmarschalls Lage des Staatsrates als unhaltbar und Regierungsbildung als ausgeschlossen betrachtet. Alle aktivistischen Parteien protestieren bei Staatsrat gegen diese Wendung. Das nationale Zentrum hebt in einem, auch Baron Konopka überreichten Protest unter anderen hervor, dass dieser „Anschlag" gegen Charakter Legionen als Kader alle Grundlagen zu einer Mitwirkung mit den Zentralmächten vernichte wïrde.

Staatrat tritt heute zur vertraulichen Besprechung zusammen.

Tekst odszyfrowanej depeszy, maszynopis.

Haus, - Hof und Staatsarchiv, Krieg, PA I, karton 1025, plik 56 c Juli August, folio 167-168.

\section{Dokument nr 46}

1917 sierpień, czwartek po 20 sierpnia, Kraków. - Rzekomy projekt polskich socjalistów w sprawie powotania nowych Legionów Polskich w Galicji i przyjęcia do takiej formacji tych wojskowych, którzy w lipcu 1917 r. byli przeciwnikami ztożenia przysięgi.

Das Präsidium des Polenklubs soll Donnerstag beim Grafen Czernin intervenieren um für die sogenanten polnischen Soldaten, darunter werden verstanden Legionäre welche österreichische Untertanen sind un ihre Entlassung aus den Legionen gebeten haben und Legionäre aus Königreich Polen, 
welche den Eid verweigert haben, wieder Sammelstationen in Galizien zu eröffnen.

Die in diesen Sammelstationen zusammengebrachten Legionäre sollen eine neue polnische Legion in Österreich bilden ud unter dem Kommando der demissionierten Legionsobersten Roja, Smigły und Norwid stehen, welche gegen die Ablegung des Eides agitiert haben und Ahänger Piłsudskis sind.

Um diese Organisation der „freien Soldaten” zu unterstützen soll an Stelle des Obersten Polnischen Nationalen Komitee's ${ }^{1}$ eine neue Organisation nach Muster der gewesenen "Provisorischen Kommission" ${ }^{2}$ geschaffen werden. Zu diesem Zwecke sind bereits die intimsten Vertrauensmänner Piłsudskis: Sokolnicki, Wasilewski, Redlinski und andere nach Krakau gekommen.

Der Zweck der Aufstellung der neuen Legionen ist folgender:

1. Um das den Legionären gegebene Versprechen zu erfïllen, dass falls sie den Eid nicht ablegen werden Österreich aus ihren Reihen eine neue Legion aufstellen werde.

2. Damit Piłsudski und die Sozialisten eine von ihnen abhängige Wehrmacht haben.

3. Um die Legionen in Warschau zu zersprengen weil dieselben dutsche Söldner sind.

4. Um eine Grundlage zur Schaffung einer neuen Organisation mit nationalen Charkter zu haben, die ein Werkzeug der politischen Agitation der Sozialisten sein soleten.

Tłumacznie $z$ języka polskiego, maszynopis.

Haus, - Hof und Staatsarchiv, Krieg, PA I, karton 1025, plik $\beta$, folio 118-119.

1 Chodzi o Naczelny Komitet Narodowy (NKN).

2 Chodzi o Komisję Tymczasową Skonfederowanych Stronnictw Niepodległościowych - KTSSN. 